OPEN ACCESS

Edited by:

Paul R. Gilson,

Burnet Institute, Australia

Reviewed by:

Miryam Andrea Hortua Triana, University of Georgia, United States

Carsten Lüder,

Universitätsmedizin Göttingen,

Germany

*Correspondence:

Matthew A. Child

m.child@imperial.ac.uk

Specialty section: This article was submitted to

Parasite and Host,

a section of the journal

Frontiers in Cellular and

Infection Microbiology

Received: 21 June 2021

Accepted: 26 July 2021

Published: 10 August 2021

Citation:

Alves E, Benns HJ, Magnus L, Dominicus C, Dobai T, Blight J, Wincott CJ and Child MA (2021) An Extracellular Redox Signal Triggers

Calcium Release and Impacts

the Asexual Development

of Toxoplasma gondii.

Front. Cell. Infect. Microbiol. 11:728425.

doi: 10.3389/fcimb.2021.728425

\section{An Extracellular Redox Signal Triggers Calcium Release and Impacts the Asexual Development of Toxoplasma gondii}

\author{
Eduardo Alves ${ }^{1}$, Henry J. Benns ${ }^{1,2}$, Lilian Magnus ${ }^{1}$, Caia Dominicus ${ }^{3}$, Tamás Dobai ${ }^{1}$, \\ Joshua Blight ${ }^{1}$, Ceire J. Wincott ${ }^{1}$ and Matthew A. Child ${ }^{1 *}$ \\ ${ }^{1}$ Department of Life Sciences, Imperial College London, London, United Kingdom, ${ }^{2}$ Department of Chemistry, Imperial \\ College London, London, United Kingdom, ${ }^{3}$ Signaling in Apicomplexan Parasites Laboratory, The Francis Crick Institute, \\ London, United Kingdom
}

The ability of an organism to sense and respond to environmental redox fluctuations relies on a signaling network that is incompletely understood in apicomplexan parasites such as Toxoplasma gondii. The impact of changes in redox upon the development of this intracellular parasite is not known. Here, we provide a revised collection of 58 genes containing domains related to canonical antioxidant function, with their encoded proteins widely dispersed throughout different cellular compartments. We demonstrate that addition of exogenous $\mathrm{H}_{2} \mathrm{O}_{2}$ to human fibroblasts infected with $T$. gondii triggers a $\mathrm{Ca}^{2+}$ flux in the cytosol of intracellular parasites that can induce egress. In line with existing models, egress triggered by exogenous $\mathrm{H}_{2} \mathrm{O}_{2}$ is reliant upon both Calcium-Dependent Protein Kinase 3 and diacylglycerol kinases. Finally, we show that the overexpression a glutaredoxin-roGFP2 redox sensor fusion protein in the parasitophorous vacuole severely impacts parasite replication. These data highlight the rich redox network that exists in T. gondii, evidencing a link between extracellular redox and intracellular $\mathrm{Ca}^{2+}$ signaling that can culminate in parasite egress. Our findings also indicate that the redox potential of the intracellular environment contributes to normal parasite growth. Combined, our findings highlight the important role of redox as an unexplored regulator of parasite biology.

Keywords: toxoplasma, redox, egress, calcium, signaling

\section{INTRODUCTION}

Toxoplasma gondii is a single-cell obligate intracellular parasite from the Apicomplexa phylum that can infect any warm-blooded animal. Its seroprevalence is estimated at more than one-third of the human population (Halonen and Weiss, 2013; Flegr et al., 2014). Within the host, the asexual lifecycle of T. gondii exists as two distinct stages: rapidly proliferating tachyzoites that characterize the acute infection, and slower replicating encysted bradyzoites that are associated with chronic infection (Sheffield and Melton, 1968; Dubey, 1996). While infections are usually benign, in immunocompromised patients and foetuses (Luft and Remington, 1992; Weiss and Dubey, 2009) the lytic tachyzoite lifecycle is responsible for severe clinical pathology. During a lytic cycle, 
tachyzoites attach onto and actively penetrate host cells, forming a permissive replication niche called the parasitophorous vacuole (PV). Parasites then replicate by endodyogeny (Goldman et al., 1958) until they eventually egress from the host cell, leading to its lytic destruction. The interconversion of virulent tachyzoites with persistent encysted bradyzoites is influenced by host immune pressure and is key to understanding disease recrudescence (Montoya and Liesenfeld, 2004). The ability of T. gondii to infect diverse host species relates to its remarkable capacity to resist host defences, efficiently recognize and quickly respond to myriad environmental clues. Among biological signal cascades activated by external clues, $\mathrm{Ca}^{2+}$ signaling is the most notable and best studied in T. gondii [reviewed in (Lourido and Moreno, 2015)]. $\mathrm{Ca}^{2+}$ is a ubiquitous signaling molecule with a vital role in tachyzoite host-cell invasion (Vieira and Moreno, 2000; Pace et al., 2014), motility (Wetzel et al., 2004) and egress (Endo et al., 1982) through activation of effector proteins such as the plant like $\mathrm{Ca}^{2+}$-dependent Protein Kinase 1 (CDPK1) (Murphy et al., 2010; Ojo et al., 2010) and CDPK3 (Garrison et al., 2012). Alongside $\mathrm{Ca}^{2+}$, other intracellular signaling molecules are known to play important roles in the tachyzoite lytic cycle. These include phosphatidic acid (PA) (Bullen et al., 2016), and the activation of protein kinase $G$ by cyclic guanidine monophosphate (cGMP) (Brown et al., 2016).

Contrasting with $\mathrm{Ca}^{2+}$, the study of reactive oxygen species (ROS) as signaling molecules is incipient in the Apicomplexa. Hydrogen peroxide $\left(\mathrm{H}_{2} \mathrm{O}_{2}\right)$ is a neutral ROS molecule with an ability to cross membranes (Guzik et al., 2000), and its roles in signaling are diverse. These include its interaction with glutathione (GSH), and the oxidation of cysteine residues leading to allosteric changes in a variety of proteins such as phosphatases, transcription factors and ion channels (Winterbourn and Hampton, 2008). Typically, the oxidation of redox-sensitive cysteines is a reversible process catalysed by enzymes that use GSH or nicotinamide adenine dinucleotide phosphatase (NADPH) (Xiong et al., 2011; Pastore and Piemonte, 2012; Sabens Liedhegner et al., 2012; Popov, 2014) as redox cofactors. Most studies of $\mathrm{H}_{2} \mathrm{O}_{2}$ and T. gondii tachyzoites have focused on the ability of host cells to use the damaging oxidative properties of ROS as a component of innate defence, and strategies employed by tachyzoites to overcome this defence (Murray and Cohn, 1979; Ding et al., 2004; Akerman and Muller, 2005; Luder and Gross, 2005; Luder et al., 2009).

A T. gondii orthologue of the $\mathrm{H}_{2} \mathrm{O}_{2}$-detoxifying enzyme catalase is expressed in the parasite cytosol, and confers protection against host oxidative stress (Kaasch and Joiner, 2000; Ding et al., 2004). In 2004 Ding et al. (2004), compiled a group of 14 genes related to the T. gondii antioxidant system. These typically localized to the parasite cytosol and mitochondria, and were assigned to one of five major redox system classifications: (1) metabolic genes (e.g. superoxidedismutase and catalase); (2) thioredoxins (Trxs, proteins that promote cysteine thiol-disulfide exchange); (3) Protein Disulfide Isomerases (PDIs, proteins that disrupt or form cysteine disulfide bonds to assist protein folding); (4) glutaredoxin-glutathione (Grx$\mathrm{GSH}$, small proteins that use GSH as a cofactor for thiol-disulfide exchange) and (5) peroxiredoxins (Prxs, enzymes that detoxify hydroperoxides like $\mathrm{H}_{2} \mathrm{O}_{2}$ and organic hydroperoxides).
Expanding this broad description of the parasite's antioxidant system, other studies have tested the association of redox with $T$. gondii signaling and cell cycle regulation. Exogenous treatment of intracellular parasites with the reducing agent dithiothreitol (DTT) triggers $\mathrm{Ca}^{2+}$ mobilization and parasite egress (Stommel et al., 1997). This egress response was triggered by the depletion of host-cell ATP resulting from the activity of an exported parasite ATPase (Silverman et al., 1998). In a separate study, the oxidation-sensitive protein $T g \mathrm{DJ}-1$ was found to associate with CDPK1 and promote microneme secretion in T. gondii (Child et al., 2017). More recently, oxidative stress (generated by sodium arsenite) has been shown to trigger tachyzoite differentiation into bradyzoites following phosphorylation of $T$. gondii eIF $2 \alpha$ (TgIF $2 \alpha$ ) by the translation initiation factor kinase TgIF2K-B (Augusto et al., 2020). Together, these data suggest that $T$. gondii modulates biological processes in response to changes in redox homeostasis.

Here, we use an in silico approach to establish a compendium of redox-associated genes and provide an updated view of these genes in T. gondii. We then investigate the impact of $\mathrm{H}_{2} \mathrm{O}_{2}$ upon parasite biology, demonstrating that $\mathrm{H}_{2} \mathrm{O}_{2}$ signal outside the boundaries of the infected host cell can be received and interpreted deep within the cytosol of intracellular parasites. We find that exogenous treatment of $\mathrm{H}_{2} \mathrm{O}_{2}$ triggers mobilization of $\mathrm{Ca}^{2+}$ culminating in CDPK3-dependent egress. Finally, we use a genetically encoded redox reporter to dissect redox oscillations prior to egress. Unexpectedly, we discover that overexpression of the active catalytic domain of a human Grx in the parasite's cytosol or PV delays parasite asexual replication. Our results corroborate the existence of a rich variety of antioxidant proteins located in multiples cellular compartments and highlight importance of redox in the basic biology of T. gondii.

\section{MATERIAL AND METHODS}

\section{Parasite and Host Cell Culture}

T. gondii tachyzoites from strain RH (Type I) lacking hypoxanthineguanine phosphoribosyl transferase gene (HXGPRT) were cultivated in vitro on monolayers of primary human foreskin fibroblast (HFF, ATTC $^{\circledR}$ ) in a humidified incubator at $37^{\circ} \mathrm{C}, 5 \%$ $\mathrm{CO}_{2}, 3 \% \mathrm{O}_{2}$ atmosphere and maintained in Dulbecco's Modified Eagle medium (DMEM) supplemented with $10 \%$ of foetal bovine serum (FBS) and 2mM L-glutamine, without antibiotics. All culture were tested against Mycoplasma infection on a monthly basis.

\section{Generation of Plasmids and Transgenic Parasites}

All primers used in this study are listed in Supplementary Table 2. The GRX1-roGFP2 sensor (Meyer et al., 2007; Aller et al., 2013) was amplified from the commercially available vector pEIGWGRX1-roGFP2 (Addgene plasmid n64990) using primers $1 / 2$ and insert into digested (HF-EcoRI \& PacI) pTUB8 vector containing selectable marker for HXGPRT using Gibson Assembly ${ }^{\circledR}$ Master Mix. The same strategy was used for GRA8-GRX1-roGFP2, using primers $2 / 3$. To generate vectors with the inactivated GRX1 
catalytic domain $\left(\mathrm{GRX}_{\text {cys23-26 }}\right)$ (Sun et al., 1998; Yang et al., 1998), primers $4 / 5$ were used to replace cysteine with a serine on pTUB8::GRX1-roGFP2 and primers $4 / 6$ on pTUB8::GRA8GRX1-roGFP2, followed circularization with KLD reaction mix (NEB), resulting the vectors pTUB8::GRX1 ${ }_{(\operatorname{ser} 23-26)}$-roGFP2 and pTUB8::GRA8-GRX1 $1_{\text {(ser23-26)-roGFP2. All vectors were linearized }}$ and transfected into RH $\Delta k u 80 \triangle H X G P R T$ parasites as previously described (Soldati and Boothroyd, 1993). Transfected parasites were selected $24 \mathrm{hrs}$ post-transfection by addition of mycophenolic acid (MPA; 25 $\mathrm{g} / \mathrm{mL}$ ) and xanthine (XAN; 50 $\mu \mathrm{g} / \mathrm{mL}$ ) to culture medium. Strains were cloned by limiting dilution into 96 well plates, and five clones selected. Genomic DNA was extracted from extracellular tachyzoites using Monarch ${ }^{\circledR}$ Genomic DNA Purification Kit (New England BioLabs). Presence of GRX1-based sensors was confirmed using primer pair $7 / 8$.

To generate the calcium sensor construct pUPRT::GFP-T2AjRCaMP1b, sequence encoding the red fluorescent calcium sensor protein jRCaMP1b (Dana et al., 2016) was ordered from IDT as a custom synthetic gene, and PCR amplified with appropriate Gibson overhangs using primers 9/10. The 5'UTR of GRA1 was PCR amplified from pTKO2c (Caffaro et al., 2013) using primers $11 / 12$, and the GFP-T2A fusion sequence was amplified from an unpublished in-house plasmid using primers 13/14. All three fragments were subsequently cloned by Gibson assembly into PacI-digested UPRT targeting vector pUPRT-HA (Reese et al., 2011). The resulting construct was linearised using NaeI and transfected into RH $\Delta k u 80 \Delta h x g$ prt parasites to generate the GFP-T2A-jRCaMP1b calcium sensor line. Transgenic parasites were subjected to 5'-fluo-2'-deoxyuridine (FUDR) selection $(5 \mu \mathrm{M}) 24 \mathrm{hrs}$ after transfection. To generate the GFP-T2A-jRCaMP1b $\triangle C D P K 3$ line, the HXGPRT casette (flanked by 5' and 3' DHFR UTR sequences) was PCR amplified from pGRA-HA_HXGPRT (Coppens et al., 2006) using primers 15/16 (introducing 40bp CDPK3 homology regions to the amplified fragment) and co-transfected into $\mathrm{RH}$ $\triangle k u 80 \triangle H X G P R T$ with pSag1::Cas9-U6::dbl-sgCDPK3. The pSag1::Cas9-U6::dbl-sgCDPK3 vector was generated by inverse PCR amplification of the pSag1::Cas9-U6 (Behnke et al., 2014) vector using primer pairs $17 / 18$ and $17 / 19$ to generate intermediate constructs pSag1::Cas9-U6::sg1CDPK3 (comprising sgRNA1) and pSag1::Cas9-U6::sg2CDPK3 (comprising sgRNA2) respectively. Following circularization of both intermediate constructs using KLD reaction mix, a region comprising sgRNA1 was PCR amplified with primers 20/21 from pSag1::Cas9-U6::sg1CDPK3 and Gibson assembled into Kpn1/ XhoI linearised pSag1::Cas9-U6:: sg2CDPK3 to generate the double sgRNA plasmid pSag1::Cas9-U6::dbl-sgCDPK3. Recombinant parasites were selected 24 hrs post transfection as previously described for GRX1-roGFP2. Integration of the HXGPRT cassette at the CDPK3 locus was confirmed using primer pairs $22 / 23$ and $24 / 25$ to confirm 5' and $3^{\prime}$ integration respectively. Absence of the endogenous CDPK3 locus was confirmed using primers 26/27. RH-GFP-Luc parasites [expressing GFP mutant 3 and firefly luciferase IAV (Ploemen et al., 2009)] were a gift from Dr Moritz Treeck.

\section{Identification of T. gondii Genes Related to Redox}

Within the Toxoplasma database (ToxoDB (Gajria et al., 2008), release 50 beta 17 Dec 2020), a list of genes related to redox signaling in $T$. gondii were obtained using the keywords "thioredoxin", "glutathione", "glutaredoxin", "peroxiredoxin" and "protein disulfide" on gene text search option. The function domains of the canonical antioxidant groups Trxs, Grx-GSH, Prxs and PDIs were confirmed for each gene using Basic Local Alignment Search Tool (BLAST) at National Center for Biotechnology information (NCBI) database (www.ncbi.nlm. nih.gov/). The spatial protein localization related to each redox gene were extracted from the localisation of organelle proteins by isotope tagging (hyperLOPIT) (Crook et al., 2018; Barylyuk et al., 2020) dataset available through ToxoDB.

\section{Plaque and Replication Assays}

For plaque assays, tachyzoites were harvested from infected HFF by syringe passage followed by filtration $(5 \mu \mathrm{m}) . \sim 100$ tachyzoites were added per well of a 6 -well plate prepared with confluent HFF monolayers, and allowed to grow undisturbed for 6 days. Plates were washed with phosphate-buffer saline (PBS) and fixed with cold methanol, stained with crystal violet and scanned. Plaque counts and area measurements were performed using FIJI software by drawing region of interesting (ROI). For replication assays, the freshly lysed tachyzoites were added to HFF monolayers grown on a $\mu$-slide 8 well glass bottom chamber $\left(\right.$ Ibidi $\left.^{\circledR}\right)$ with multiplicity of infection (MOI) 1 . To synchronize the infection, parasites were allowed to settle onto chilled host cells for 20 minutes, and then allowed to invade for 2 hours at $37^{\circ} \mathrm{C}$. Cells were washed with PBS to remove extracellular tachyzoites. Cells were incubated for a further 18 hours, and subsequently fixed with $3 \%$ paraformaldehyde at room temperature (RT) for $20 \mathrm{~min}$, and blocked with PBS supplemented with $2 \%$ FBS. Parasites per vacuole were counted by excitation with $470 \mathrm{~nm}$ laser ( $4 \%$ intensity) widefield Nikon Eclipse Ti-E inverted microscope equipped with an ORCA- Flash4.0 camera (Hamamatsu, Japan) and NIS-Elements Viewer software (Nikon), 60x-oil objective. All parasite strains were genetically encoding for GFP or roGFP2. All strains were tested tree independent times, each with three technical replicates.

\section{Egress Assay}

Freshly lysed tachyzoites from RH-GFP-t2a-jRCaMP1b or RHGFP-T2A-jRCaMP1b $\triangle C D P K 3$ parasites were harvested and inoculated (MOI:1) onto confluent HFF cells grown on 24 well plates and grown for 18 hours. Cells were washed with PBS and the growth medium replaced with phenol red free DMEM without FBS and incubate for a further three hours. Medium was removed and cells were incubated for 30 minutes with PBS plus drugs (A23187, $\mathrm{R} 59022, \mathrm{H}_{2} \mathrm{O}_{2}$ ) or vehicle controls (water, DMSO). At the end of incubation, the supernatant of the wells was carefully aspirated and cells were detached by $10 \mathrm{~min}$ incubation with $200 \mu \mathrm{L}$ of RT Accutase ${ }^{\mathrm{TM}}$. Accutase-release cell suspensions were fixed with $200 \mu \mathrm{L}$ of $8 \%$ paraformaldehyde 
(20 minutes, RT). Fixed cells were transferred into falcon $5 \mathrm{~mL}$ tube with $35 \mu \mathrm{m}$ nylon mesh cap. Free fluorescent parasite and infected HFF population were analysed and quantified in a BD LRSFortessa $^{\mathrm{TM}}$. A total of 5000 events were collected for each tube. Blue laser $(488 \mathrm{~nm})$ with $530 / 30 \mathrm{~nm}$ filter was used to detect the GFP signal. An uninfected HFF control was used to assess the effect of each drug treatment on host cell gating. Each drug condition was tested three independent times, each with six technical replicates.

\section{Fluorescence Microscopy}

For cytosolic $\mathrm{Ca}^{2+}$ fluorometric measurements, RH-GFP-T2AjRCaMP1b or RH-GFP-T2A-jRCaMP1b $\triangle C D P K 3$ parasites were added (MOI:1) to confluent HFF grown on 8 well glass bottom chamber and allowed to grow for 18 hours. Wells were washed with PBS and media replaced by phenol red-free DMEM medium without FBS, and incubate for a further two hours. Images of live infected HFFs were captured at $37^{\circ} \mathrm{C}$, using a $60 \mathrm{x}-$ oil objective in the same widefield microscope previously describe on replication assay. Only vacuoles containing 4 to 8 parasites were considered for data analyses. GFP (470 nm excitation/520 nm emission) and jRCaMP1b (555 nm excitation/605 nm emission) with 100 milliseconds acquisition rate signal were collected every second for up to a maximum 10 minutes. Drugs were applied on the wells after one minute of acquisition by pipetting. Image analyses were performed using FIJI software. Raw fluorescence readout (F) for each vacuole on each channel was normalised against the average of the baseline signal before adding the drug $\left(\mathrm{F}_{0}\right)$ using the ratio $\mathrm{F} / \mathrm{F}_{0}$ bringing the resting baseline value to one. To distinguish intracellular $\mathrm{Ca}^{2+}$ oscillation signal from vacuole movement, the $\mathrm{F}_{(\mathrm{jRCaMP} 1 \mathrm{~b})} / \mathrm{F}_{0}$ (jRCaMP1b) values were normalised against the GFP signal $\mathrm{F}_{(\mathrm{GFP})} /$ $\mathrm{F}_{0 \text { (GFP) }} \cdot \mathrm{Ca}^{2+}$ response during a specific time is given by the formula: $\left(\mathrm{F}_{(\mathrm{jRCaMP} 1 \mathrm{~b})} / \mathrm{F}_{0(\mathrm{j} \text { RCaMP } 1 \mathrm{~b})}\right) /\left(\mathrm{F}_{(\mathrm{GFP})} / \mathrm{F}_{0(\mathrm{GFP})}\right)$.

For redox measurements, parasites expressing ratiometric GRX1 based sensors were treated as described for RH-GFP-T2AjRCaMP1b parasites. Oxidized GRX1-roGFP2 (395 nm excitation/ $520 \mathrm{~nm}$ emission) and reduced GRX1-roGFP2 (470 nm excitation/ $520 \mathrm{~nm}$ emission) with 200 milliseconds acquisition rate signal were collected every second for up to a maximum 10 minutes. Data analyses is similar to $\mathrm{Ca}^{2+}$, the redox reading was obtained by formula: $\left(\mathrm{F}_{\text {(oxidised) }} / \mathrm{F}_{0 \text { (oxidised) }}\right) /\left(\mathrm{F}_{\text {(reduced) }} / \mathrm{F}_{0 \text { (reduced) })}\right.$.

\section{Chemical and Reagents}

Hydrogen peroxide 30\% (w/w) solution with stabilizer; diacylglycerol kinase inhibitor (R59022); A23187, Ionomycin, anhydrous methanol, and crystal violet solution were obtained from Sigma-Aldrich Company Ltd. $\alpha$-tocopherol phosphate disodium salt from Merk. Dimethylsulfoxide (DMSO) anhydrous and paraformaldehyde 16\% solution from Life Technologies. Accutase cell detachment solution from Fisher Scientific Ltd.

\section{Statistical Analysis}

The data are represented as the mean \pm SEM and analysed using two-tailed paired Student $t$ test between two groups and one-way or 2 way analyses of variance (ANOVA) with Bonferroni's multiple comparisons test for comparing means between $\geq 3$. All data were analysed using GraphPad Prism 9 software (California, USA). The data were considered statistically significant when $\mathrm{P}$ values $<0.05$.

\section{RESULTS}

\section{An Updated Compendium of T. gondii Redox-Associated Genes}

We initially sought to update our understanding of the antioxidant response and redox-signaling network in T. gondii. We mined gene sequence and annotation information, as well as proteomic datasets present on ToxoDB (Gajria et al., 2008) to update the list of 14 redox associated genes previously summarised by Ding et al. (2004). Our bioinformatic approach screened for genes containing at least one functional domain of the major redox signaling groups (Trxs, PDIs, Grx-GSHs and Prxs). We identified a total of 58 redox-associated genes (Supplementary Table 1), including 26 Trxs, 16 GRX-GSHs, six PDIs, six Prxs, and four metabolic genes (including three distinct superoxide dismutases and one catalase). With the exception of the metabolic genes (Sibley et al., 1986; Kaasch and Joiner, 2000; Odberg-Ferragut et al., 2000; Ding et al., 2004), the majority of genes representing the other redox signaling groups remain uncharacterized. For an improved view of the subcellular distribution of these gene products, we extracted their primary localisation from the recently published hyperLOPIT dataset (Barylyuk et al., 2020) (Figure 1 and Supplementary Table 1). This indicated a broad distribution of these proteins throughout the cell and suggested the existence of spatially distinct mechanisms of redox regulation for different subcellular compartments.

\section{Extracellular Hydrogen Peroxide Induces Cytosolic $\mathrm{Ca}^{2+}$ Flux in Intracellular Tachyzoites}

In other eukaryotic systems there are clear associations between calcium and redox signaling. For example, oxidation of cysteines on the ryanodine receptor stimulates calcium release from intracellular compartments (Meissner, 2002; Oda et al., 2015). To investigate if a similar overlap exists between these two signaling networks in $T$. gondii, we tested the ability of $\mathrm{H}_{2} \mathrm{O}_{2}$ to trigger a $\mathrm{Ca}^{2+}$ response in tachyzoites within a host cell. We generated a Type 1 parasite $(\mathrm{RH}$ strain) expressing the $\mathrm{Ca}^{2+}$ sensor protein jRCamP1b (Dana et al., 2016) fused to GFP via the T2A peptide for bicistronic protein expression (referred to as RH-GFP-T2A-jRCaMP1b). The jRCaMP1b is a bright red fluorescent sensor for $\mathrm{Ca}^{2+}$ with an improved dynamic range and kinetic compared to $\mathrm{jRCaMP1a}$ (Dana et al., 2016). The ratio of these two distinct fluorescent proteins provided an elegant tool to distinguish changes in fluorescence due to cell movement from the $\mathrm{Ca}^{2+}$ signal (Figure 2 and Supplementary Figures 1A, B). Upon exogenous addition of $100 \mu \mathrm{M} \mathrm{H}_{2} \mathrm{O}_{2}$ we observed a distinct increase in the intracellular $\mathrm{Ca}^{2+}$ reporter signal (Figure 2A and Supplementary Videos 1-3). To determine whether the oxidative properties of $\mathrm{H}_{2} \mathrm{O}_{2}$ are responsible for triggering parasite $\mathrm{Ca}^{2+}$ release, we repeated the experiment in the presence of the antioxidant $\alpha$-tocopherol (Figure 2B). 


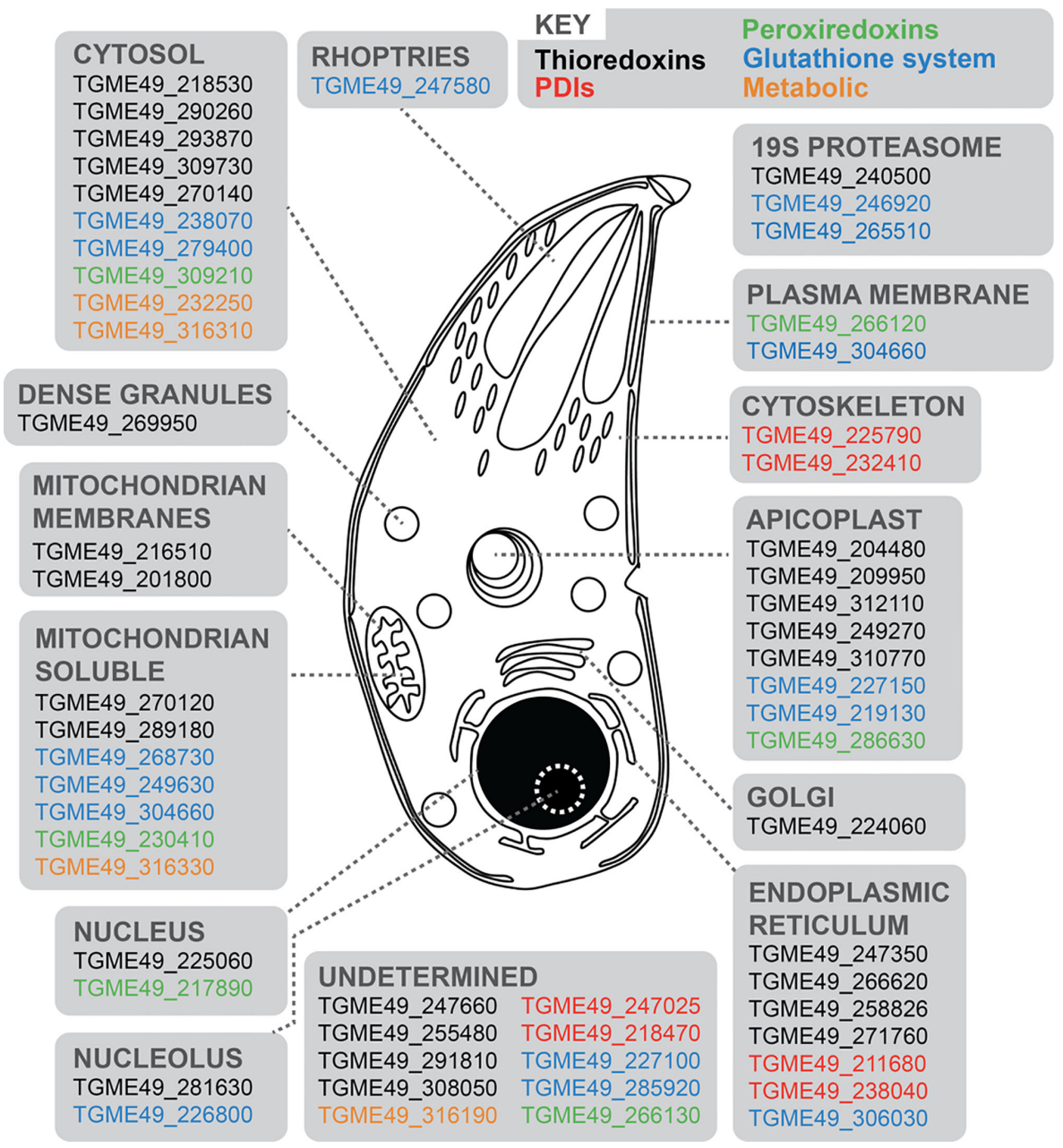

FIGURE 1 | Schematic representation of a T. gondii tachyzoite displaying 58 redox-associated genes, and their primary protein location as determined by HyperLOPIT (Barylyuk et al., 2020). Gene ID accession numbers are provided, and genes categorized into five groups: black (Trxs); red (PDIs); green (Prxs); blue (Grx-GSHs) and orange (metabolic genes). Further details are provided in Supplementary Table 1.

Pre-treatment of infected host cell monolayers with $50 \mu \mathrm{M} \alpha$ tocopherol abolished $\mathrm{H}_{2} \mathrm{O}_{2}$-stimulated $\mathrm{Ca}^{2+}$ release in intracellular parasites. The addition of the $\mathrm{Ca}^{2+}$ ionophore $\mathrm{A} 23187$ caused an intense $\mathrm{Ca}^{2+}$ signal spike in the parasite cytosol in both the presence and absence $\alpha$-tocopherol (Figures 2A, B, respectively), suggesting that the presence of the antioxidant does not interfere with $\mathrm{Ca}^{2+}$ stores in intracellular parasites. Vehicle solvent for $\mathrm{H}_{2} \mathrm{O}_{2}$ (water) and for A231877 (DMSO) did not trigger $\mathrm{Ca}^{2+}$ mobilisation (Figure 2 and Supplementary Figures 1C, D, respectively).

We compared the magnitude of the $\mathrm{Ca}^{2+}$ signal increase following $\mathrm{H}_{2} \mathrm{O}_{2}$ treatment with the increase triggered by $\mathrm{A} 23187$, a small molecule known to induce parasite egress by $\mathrm{Ca}^{2+}$ -dependent mechanisms (Black et al., 2000) (Figure 2C). $\mathrm{H}_{2} \mathrm{O}_{2}$ induced an overall $\mathrm{Ca}^{2+}$ signal increase of $35 \% \pm 1.7$. This was lower than the $\mathrm{Ca}^{2+}$ signal increase observed when parasites were treated with A23187 alone (140 \pm 4.3$)$, or A23187 on cells pre-treated with $100 \mu \mathrm{M} \mathrm{H}_{2} \mathrm{O}_{2}(61 \% \pm 0.9)$. Within restricted timeframe of this experiment (10 minutes), a single egress event was observed for cells treated with $100 \mu \mathrm{M} \mathrm{H}_{2} \mathrm{O}_{2}$ (Figure 2C and Supplementary Video 2). Observation of egress induced by $\mathrm{H}_{2} \mathrm{O}_{2}$ was more frequent when host cells were infected with a high multiplicity of infection (MOI = 5) (Figure 2 and Supplementary Video 3). We also measured the magnitude of $\mathrm{Ca}^{2+}$ signal increase induced by $\mathrm{H}_{2} \mathrm{O}_{2}$ in $\triangle C D P K 3$ parasites (Figure 2D). The magnitude of the $\mathrm{Ca}^{2+}$ signal induced by $\mathrm{H}_{2} \mathrm{O}_{2}$ in RH-GFP-T2A-jRCaMP1b $\triangle C D P K 3$ was lower $(18.1 \% \pm$ 4.3) compared to RH-GFP-T2A-jRCaMP1b $(32.5 \% \pm 1.1)$. This could reflect previously observed differences in the resting $\mathrm{Ca}^{2+}$ levels of these lines (Treeck et al., 2014). Together, these data suggest that tachyzoites within the PV can perceive and respond to oxidation events initiated outside the host cell.

\section{Hydrogen Peroxide Induces Parasite Egress in a Mechanism Dependent on CDPK3}

Calcium flux accompanies natural egress (Stewart et al., 2017), and calcium ionophores are well-characterized inducers of egress (Endo et al., 1982). To better investigate the potential of $\mathrm{H}_{2} \mathrm{O}_{2}$ to 


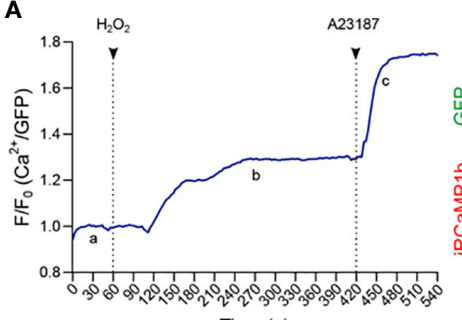

Time (s)

C

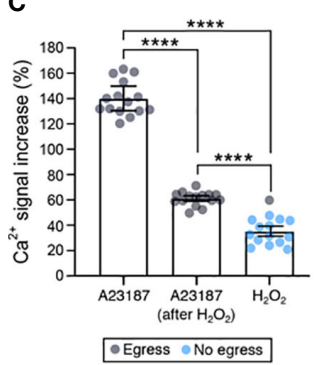

D

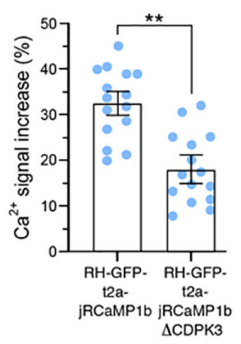

B

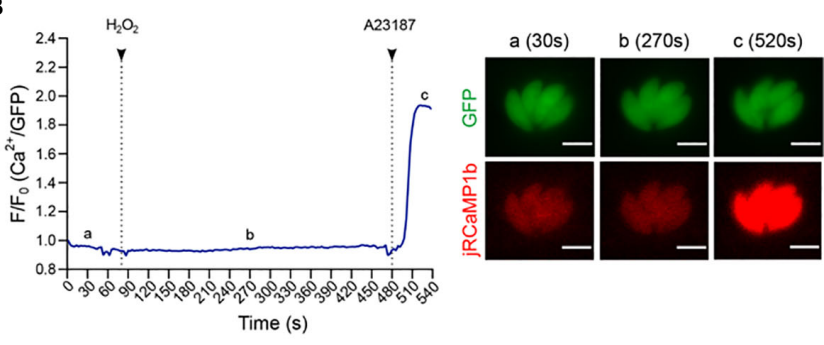

E

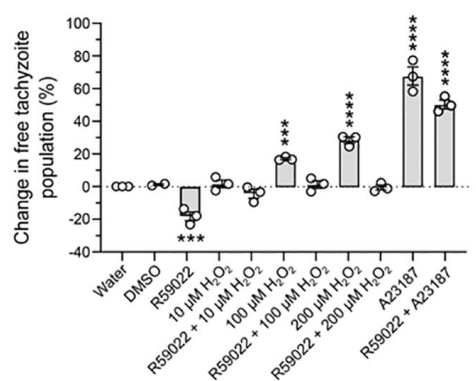

$\mathbf{F}$

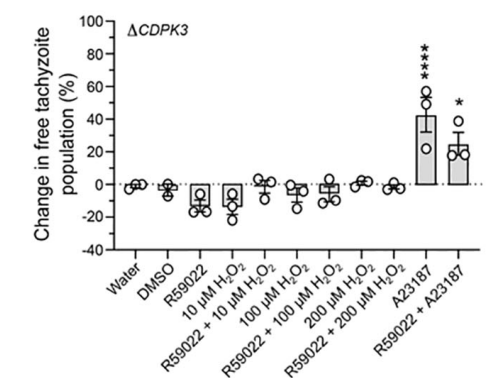

FIGURE $2 \mid \mathrm{H}_{2} \mathrm{O}_{2}$ induces $\mathrm{Ca}^{2+}$ release in intracellular parasites and triggers CDPK3-dependent egress. (A) Representative trace of $100 \mu \mathrm{M} \mathrm{H}{ }_{2} \mathrm{O}_{2}$ induction of $\mathrm{Ca}^{2+}$ flux in intracellular RH-GFP-T2A-jRCaMP1b parasites. a - c: widefield microscopy images depicting changes in parasite fluorescence signal intensity for both GFP and the $\mathrm{Ca}^{2+}$ sensor at baseline (a at 30s), the peak of $\mathrm{Ca}^{2+}$ after $\mathrm{H}_{2} \mathrm{O}_{2}$ addition (b at 270s), and peak of $\mathrm{Ca}^{2+}$ after $1 \mu \mathrm{M} \mathrm{A23187}$ addition (c at 460 s). Data are representative of 27 infected vacuoles from four independent experiments. (B) Representative trace of $100 \mu \mathrm{M} \mathrm{H}_{2} \mathrm{O}_{2}$ induction of Ca ${ }^{2+}$ flux following pre-treatment of

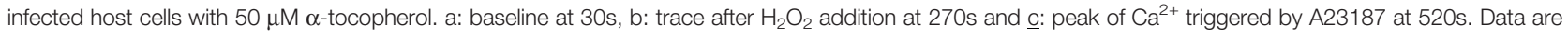
representative of 14 infected vacuoles from three independent experiments. For (A, B) black arrows indicate the time of compound addition. Scale bar: $5 \mu \mathrm{M}$. (C) Intensity of parasite $\mathrm{Ca}^{2+}$ signal increase in RH-GFP-T2A-jRCaMP1b parasites (expressed as a percentage over baseline) following addition of: $1 \mu \mathrm{M}$ A23187 alone, $1 \mu \mathrm{M}$ of $\mathrm{A} 23187$ following $100 \mu \mathrm{M} \mathrm{H}_{2} \mathrm{O}_{2}$ pre-treatment, and $100 \mu \mathrm{M} \mathrm{H}_{2} \mathrm{O}_{2}$ alone. Gray dots indicate vacuole data points where parasite egress was observed during the measurement period, blue dots represent vacuoles where egress was not observed. (D) Intensity of parasite Ca ${ }^{2+}$ signal increase (\%) over the baseline upon addition of $100 \mu \mathrm{M} \mathrm{H}_{2} \mathrm{O}_{2}$ in RH-GFP-T2A-jRCaMP1b versus RH-GFP-T2A-jRCaMP1b $\Delta C D P K 3$ parasites. For (C, D) histograms present data mean \pm SEM of three independent experiments (five vacuoles measured in each experiment), with individual vacuole data points also shown. (E, F) Egress assay measuring tachyzoite release after compound treatment in RH-GFP-T2A-jRCaMP1b and RH-GFP-T2A-jRCaMP1b $\Delta C D P K 3$, respectively. Data represent the mean \pm SEM of three independent experiments (except for DMSO that has two independent experiments), with six technical replicates for each. All data were normalised to the water control. Significance was calculated using one-way Anova, Bonferroni's multiple comparisons test. $P$ values: ${ }^{\star}<0.05 ;{ }^{* \star}<0.01,{ }^{* \star *}<0.001$ and ${ }^{* \star \star \star}<0.0001$.

induce parasite egress, we analysed populations of infected host cells by flow cytometry. The GFP signal from parasites expressing the $\mathrm{Ca}^{2+}$ sensor and particle size were used to distinguish infected host cells from free tachyzoites (Figure 2 and Supplementary Figure 2A). We tested whether treatment of infected host cells with different concentrations of $\mathrm{H}_{2} \mathrm{O}_{2}$ could increase the proportion of free tachyzoites. Incubation of infected host cells with $\mathrm{H}_{2} \mathrm{O}_{2}$ resulted in a dose-dependent increase in the number of free tachyzoites (Figure 2E). We sought to understand how the $\mathrm{H}_{2} \mathrm{O}_{2}$ stimulated egress integrates into our current molecular understanding of this process. The small molecule R59022 is an inhibitor of diacylglycerol kinase (Cooke et al., 1987) that inhibits egress by disrupting the formation of phosphatidic acid (Bullen et al., 2016). For all concentration tested, treatment of cells with $\mathrm{H}_{2} \mathrm{O}_{2}$ resulted in a pharmacological rescue of R59022 egress inhibition. However in the presence of $\mathrm{R} 59022, \mathrm{H}_{2} \mathrm{O}_{2}$ did not stimulate egress above the baseline value. This could relate to the discrete points of activity for the two targets of R59022: diacylglycerol kinase 1 and 2 (Bullen et al., 2019) relative to where the $\mathrm{H}_{2} \mathrm{O}_{2}$ effect feeds into the system. The stimulation of egress by $\mathrm{H}_{2} \mathrm{O}_{2}$ was abolished in $\triangle C D P K 3$ parasites (Figure $\mathbf{2 F}$ ), demonstrating a dependency upon this kinase similar to other egress agonists such as A231287. The incubation of non-infected HFFs with different concentrations of $\mathrm{H}_{2} \mathrm{O}_{2}$ did not alter the proportion of events in this population (Figure $\mathbf{2}$ and Supplementary Figure 2B), confirming that the concentrations of $\mathrm{H}_{2} \mathrm{O}_{2}$ used in this protocol did not lyse the host cells.

\section{Intracellular Parasites Expressing GRX1- roGFP2 Sensor Perceive Oxidation Induced by $\mathrm{H}_{2} \mathrm{O}_{2}$}

After confirming that exogenous addition of $\mathrm{H}_{2} \mathrm{O}_{2}$ stimulated $\mathrm{Ca}^{2+}$ flux in intracellular T. gondii parasites, we investigated the redox state within the parasite cytosol and PV. We reasoned that if calcium release was the direct result of an oxidative signal, the redox status of cellular compartments separating intracellular parasites from the extracellular environment should also be affected. To test this, we generated transgenic parasite strains constitutively expressing the redox sensor protein GRX1-roGFP2, in two different cellular compartments: the parasite cytosol, or targeted to the PV as a consequence of an N-terminal fusion with the GRA8 signal 
sequence (Carey et al., 2000). GRX1-roGFP2 is a ratiometric redox reporter that detects changes in both reduced (GSH) and oxidized (GSSG) glutathione (Aller et al., 2013) (Figures 3A, B). Importantly, the redox relay system underpinning GRX1-roGFP2 is not affected by $\mathrm{pH}$, which is known to confound data interpretation with other redox sensor proteins (Gutscher et al., 2008). We used GRX1-roGFP2 parasites to track dynamic changes in GSH/GSSG by fluorescence microscopy, and used the normalized GSH/GSSG signal ratio to measure the intensity of oxidation events (Figure 3C and Supplementary Figure 3A). Intracellular parasites expressing the redox sensor targeted to the PV (RH-GRA8-GRX1-roGFP2) or cytosol (RH-GRX1-roGFP2) detected an oxidation event upon exogenous addition of $100 \mu \mathrm{M}$ $\mathrm{H}_{2} \mathrm{O}_{2}$ (Figures 3D, E, respectively). The oxidation event within the $\mathrm{PV}$ was of greater magnitude compared to that detected within the parasite cytosol, indicating that the strength of the oxidative signal was diminished as it crossed the biological membrane separating these compartments. The water control did not affect the redox signal from GRX1-roGFP2 sensor (Figure 3 and Supplementary Figure 3B).

Having observed that $\mathrm{H}_{2} \mathrm{O}_{2}$ could stimulate calcium flux, we investigated the reciprocal nature of this relationship by testing the ability of calcium ionophores to trigger an oxidative event. Using GRX1-roGFP2 parasites, we measured the resting redox state prior to ionomycin-induced egress. Ionomycin-induced egress was not accompanied by detectable changes in redox within either the PV or parasite cytosol (Figures 3F, G, respectively). The ionophore A23187 could not be used because of saturating autofluorescence associated with this small molecule in the fluorescence channel used to measure oxidation (Figure 3 and Supplementary Figure 3C). These data suggested that no significant change in the GSH/GSSG ratio occurs before parasite egress induced by ionomycin.

\section{GRX1-roGFP2 Redox Sensor Affects Parasite Fitness During Asexual Replication}

We noted that one unavoidable result of using the GRX1roGFP2 redox relay sensors would be the associated overexpression of the catalytic domain of glutaredoxin (as a consequence of it being fused to roGFP2). GRX1 is a small redox enzyme that confers protection against oxidative stress (Gutscher et al., 2008; Laporte et al., 2012), and the overexpression of this enzyme would be expected to shift GSH/GSSG ratios in favour of the reduced form (GSH). Correspondingly, we hypothesized that T. gondii strains overexpressing GRX1 would have their normal redox status shifted to a more reduced potential. To test whether the overexpression of this redox protein affected parasite asexual

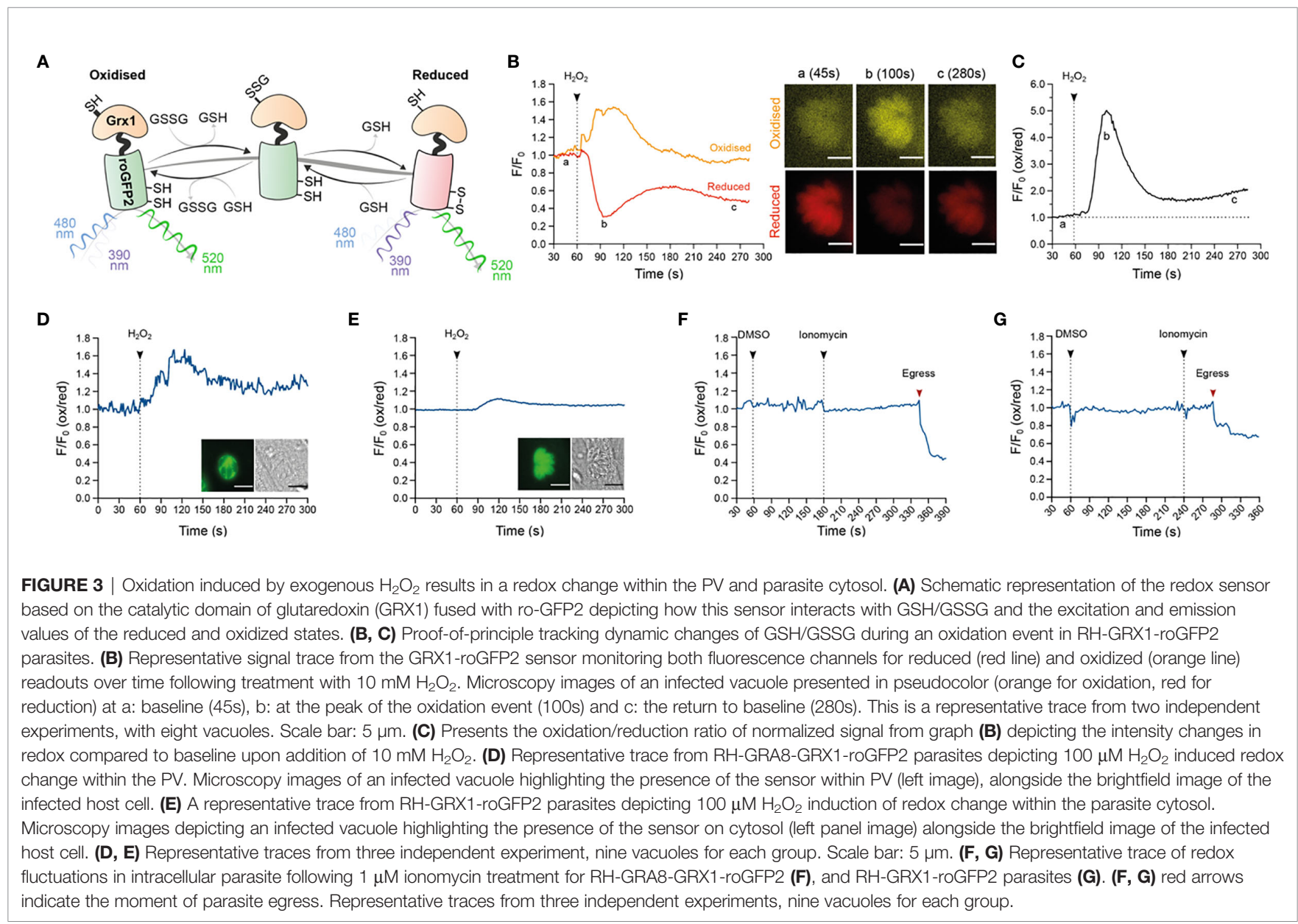


growth, we generated a transgenic parasite strain expressing a version of the redox sensor where we had mutated the key catalytic cysteine residue of GRX to render it enzymatically inactive

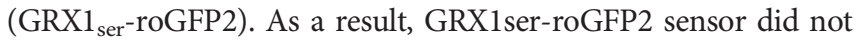
respond changes in GSH/GSSG following $\mathrm{H}_{2} \mathrm{O}_{2}$ treatment (Figure 4 and Supplementary Figure 4). We compared the growth of this strain with parasites expressing the catalytically active version of the sensor. As before, both active and inactive versions of the GRX-fusion sensor were targeted to either the parasite cytosol or PV. As a control group, we used a transgenic parasite strain expressing redox-insensitive GFP (RH-GFP-Luc) (Ploemen et al., 2009). This strain was used as a control in preference to RH $\Delta k u 80 \triangle H X G P R T$ parasites. We reasoned that it would better control for any metabolic cost and fitness impact resulting from the expression of a large non-native sensor. It would also allow for live imaging of both control and redox sensor strains in parallel. Plaque assays confirmed that RH-GFP-Luc parasites were able to form plaques on confluent monolayers of HFFs with equal efficiency to the RH $\Delta k u 80 \triangle H X G P R T$ (Figure 4A and Supplementary Figure 5). Parasites expressing catalytically active GRX1 in the cytosol presented fewer plaques compared to $\mathrm{RH}-$ GFP-Luc (Figure 4A). Despite being able to successfully maintain PV-targeted sensor strains in culture, all parasites lines where the sensor was targeted to the PV did not form clear measurable plaques

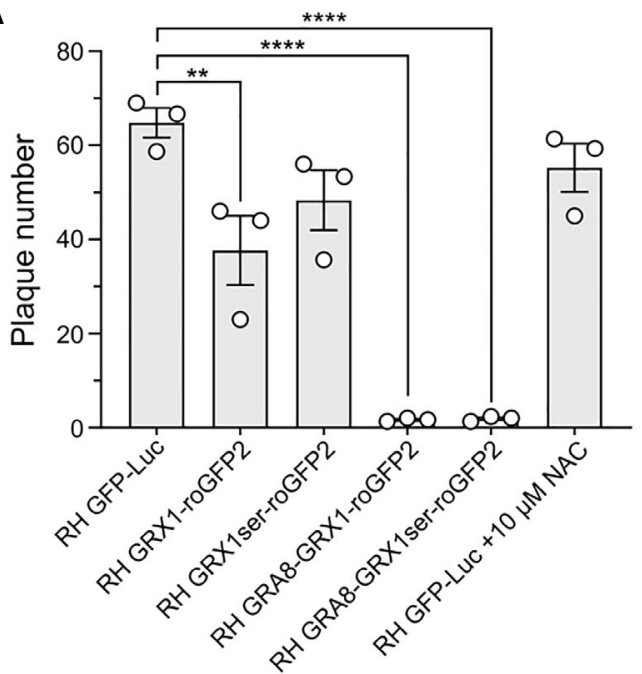

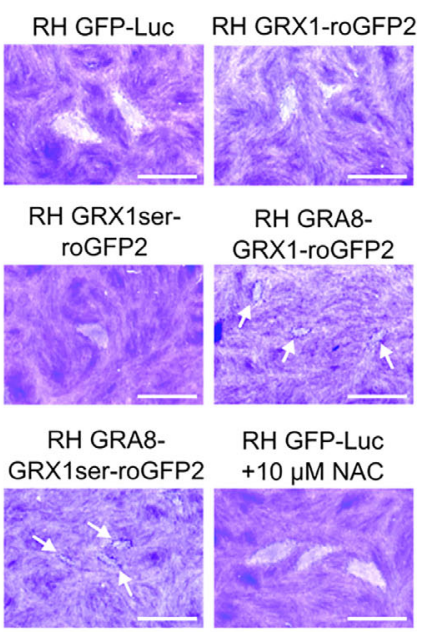

C

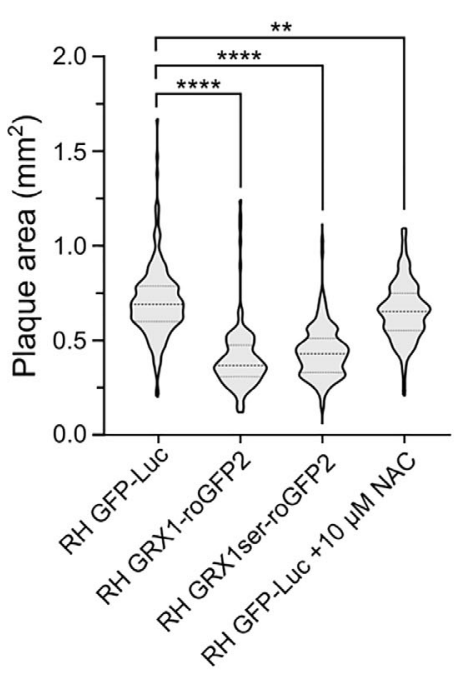

D

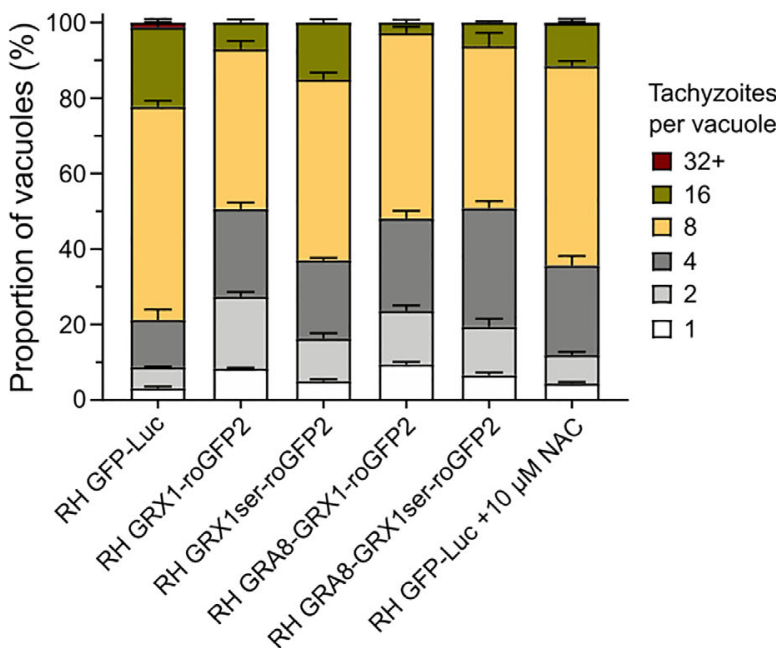

FIGURE 4 | The GRX1-roGFP redox sensor affects $T$ gondii asexual replication. (A) Bar graphs presenting plaque count data from a six-day plaque assay using RH-GFP-Luc parasites as a reference control group. (B) Representative images of plaques formed. Small plaques are indicated by white arrows. Scale bar: 2 mm. (C) Violin plot presenting the distribution of plaque areas $\left(\mathrm{mm}^{2}\right)$ for parasites expressing the redox sensor within the cytosol. (D) Histogram presenting the effect of the GRX1-roGFP sensors and NAC on parasite intracellular replication. (A-D) All obtained from three independent experiments, with three technical replicates. Significance was calculated using one-way Anova, Bonferroni's multiple comparisons test for (A, B). P values: ${ }^{\star \star}<0.01,{ }^{* \star}<0.001$ and ${ }^{* \star \star *}<0.0001$. The significance analyse for (D) is provide on Supplementary Figure 6. 
after six days of growth. Intensely stained plaque-shaped boundaries visible on the HFF monolayer suggested these parasites had successfully grown, but that parasite lytic growth had not outcompeted host cell monolayer recovery sufficiently to produce a clear zone of lysis (Figure 4B). When either the catalytically active or inactive sensors were targeted to the parasite cytosol, parasites formed smaller plaques compared to the $\mathrm{RH}$ GFP-Luc control (Figures 4B, C, respectively). These data suggested that the presence roGFP2 alone might be sufficient to affect parasite growth. To directly test the influence of redox environment on the lytic cycle, we grew RH-GFP-Luc parasites with $10 \mu \mathrm{M} \mathrm{N}$-acetyl cysteine (NAC), a small antioxidant molecule that functions by donating cysteine to increase GSH biosynthesis (Ezerina et al., 2018). Addition of NAC decreased the size of plaques generated by RH-GFP-Luc parasites (Figure 4C), suggesting that GSH/GSSG imbalance compromised parasite growth. To better understand the impact of overexpressing the sensor on parasite growth, we counted the number of parasites per vacuole after 20 hours of asexual parasite replication (Figure 4D). All strains expressing the redox sensor had reduced replication compared to RH-GFP-Luc (Figure 4D and Supplementary Figure 6), with catalytic inactivation of the GRX domain providing a partial rescue of the replication defect. Strains exhibiting the slowest replication were those where the sensor was targeted to the PV, supporting the plaque growth data in Figure 4B. Together, these data suggest parasite growth is sensitive to changes in GSH/ GSSG ratios.

\section{DISCUSSION}

Investigations of ROS and T. gondii biology initially focused on the host innate immune response. Host macrophages can generate oxidative bursts, creating a toxic microenvironment to fight microbial infection (McLeod et al., 1983; Sibley et al., 1985; Dupre-Crochet et al., 2013), with early studies interested in mechanisms used by T. gondii to evade oxidative stress (Wilson et al., 1980; Shrestha et al., 2006; Lima and Lodoen, 2019). However, increasing evidence from multiple organisms has demonstrated that $\mathrm{H}_{2} \mathrm{O}_{2}$ has functions as a signaling molecule [reviewed in (Veal and Day, 2011)], suggesting the likelihood of a more complex role for ROS in the pathophysiology of T. gondii. To sense, respond, and protect against potential oxidative damage from ROS stimuli, cells employ a network of redox-associated proteins such as Trxs, PDIs, Prxs, Grxs, superoxide dismutase and catalase. It was previously shown that T. gondii possesses all these elements (Ding et al., 2004), and we provide an update on the number, diversity and cellular distribution of these redox-associated proteins (Figure 1). The function of some of these redox-associated gene products in $T$. gondii parasites has been examined: disruption of catalase decreases parasite virulence in mice and in vitro tolerance to $\mathrm{H}_{2} \mathrm{O}_{2}$ (Ding et al., 2004); peroxiredoxin-1 interacts with histone lysine methyltransferase to likely regulate gene expression by chromatin rearrangement (Sautel et al., 2009); two thioredoxins have essential roles in apicoplast biogenesis (Biddau et al., 2018), and another thioredoxin with cytosolic localization has been associated with parasite virulence (Xue et al., 2017). Nevertheless, functional information for most of the redox-associated proteins identified in this work remains elusive.

The ability of low concentrations of $\mathrm{H}_{2} \mathrm{O}_{2}$ to initiate an intracellular $\mathrm{Ca}^{2+}$ response in mammalian systems is well documented (Roveri et al., 1992; Volk et al., 1997; Avdonin et al., 2017) and has helped to solidify $\mathrm{H}_{2} \mathrm{O}_{2}$ as a signaling molecule. Addition of antioxidants blocks intracellular $\mathrm{Ca}^{2+}$ release induced by $\mathrm{H}_{2} \mathrm{O}_{2}$ in smooth muscle cells (Roveri et al., 1992) suggesting that the oxidative properties of $\mathrm{H}_{2} \mathrm{O}_{2}$ are required for $\mathrm{Ca}^{2+}$ signaling. In human endothelial cells, oxidation induced by non-toxic concentrations of $\mathrm{H}_{2} \mathrm{O}_{2}$ target a $\mathrm{Ca}^{2+}$ channel located in acid compartments (Avdonin et al., 2017). Distinct from these models, this work is the first to report that an oxidation event induced by $\mathrm{H}_{2} \mathrm{O}_{2}$ mobilizes intracellular $\mathrm{Ca}^{2+}$ in $T$. gondii tachyzoites within the infected host cell (Figure 2A). This is the first time this has been shown for any apicomplexan parasite. Studying the parasite within the host cell provides the best approximation of physiological conditions to observe both $\mathrm{Ca}^{2+}$ and redox signaling. Moreover, using parasites expressing a genetically encoded fluorescent $\mathrm{Ca}^{2+}$ sensor abrogated the need to use fluorescent $\mathrm{Ca}^{2+}$ indicator dyes. Use of these dyes can be damaging to the cells, and typically require the use of other small molecules to avoid dye loss and compartmentalization (Di Virgilio et al., 1990). GFP coexpressed with $\mathrm{Ca}^{2+}$ sensor allows $\mathrm{Ca}^{2+}$ responses to be distinguished from parasite movement which avoids the need to use inhibitors of parasite motility such as cytochalasin D (Carter, 1967). Finally, the concentration of $100 \mu \mathrm{M} \mathrm{H}_{2} \mathrm{O}_{2}$ has been showed to be non-toxic for human fibroblast (Hyslop et al., 1995). Altogether, our protocol to investigate intracellular $\mathrm{Ca}^{2+}$ release following $\mathrm{H}_{2} \mathrm{O}_{2}$ treatment sought to avoid cellular stress that could compromise the true redox/ $\mathrm{Ca}^{2+}$ dynamic within the parasite. As previously report in muscle cells (Roveri et al., 1992), the presence of antioxidant inhibited the parasite $\mathrm{Ca}^{2+}$ response triggered by $\mathrm{H}_{2} \mathrm{O}_{2}$. Using the GRX1-roGFP2 redox sensor, we confirmed that intracellular parasites directly sense an oxidation event following the exogenous addition of $100 \mu \mathrm{M} \mathrm{H}_{2} \mathrm{O}_{2}$. It is not clear whether the exogenous addition of $100 \mu \mathrm{M}$ of $\mathrm{H}_{2} \mathrm{O}_{2}$ results in $\mathrm{H}_{2} \mathrm{O}_{2}$ reaching the intracellular parasites as the host cell contains an extensive network of antioxidant proteins that would be expected to scavenge and neutralise $\mathrm{H}_{2} \mathrm{O}_{2}$. This could be directly addressed in future experiments using $T$. gondii strains expressing a sensor to specifically detect $\mathrm{H}_{2} \mathrm{O}_{2}$ (Gutscher et al., 2009).

Regardless of whether $\mathrm{Ca}^{2+}$ is mobilized within the parasite as a direct result of an interaction with $\mathrm{H}_{2} \mathrm{O}_{2}$, or via secondary oxidation signal from the host, $\mathrm{Ca}^{2+}$ regulates all aspects of parasite host cell invasion (Lourido and Moreno, 2015) included egress (Garrison et al., 2012). For the short time period used to track parasites by microscopy, the intensity of the $\mathrm{Ca}^{2+}$ signal response induced by $\mathrm{H}_{2} \mathrm{O}_{2}$ was quite modest compared to A23187, and that likely explains why egress events were rare. Longer incubations with $\mathrm{H}_{2} \mathrm{O}_{2}$ induced parasite egress through a mechanism that requires $\mathrm{CDPK} 3$ and likely phosphatidic acid. 
Introduction of the redox sensors described in this work into the $\triangle \mathrm{CDPK} 3$ parasite background could provide direct evidence its role in the crosstalk between calcium and redox. Our work provides the first evidence that suggests that oxidation can trigger T. gondii egress. Interestingly, at the other end of the redox spectrum, the reductive molecule DDT can also mobilize $\mathrm{Ca}^{2+}$ and induce parasite egress (Stommel et al., 1997). Although the mechanism by which $\mathrm{H}_{2} \mathrm{O}_{2}$ and DDT lead to parasite egress appears to be distinct, these data indicate that redox can influence the parasite's lytic cycle. We anticipate that parasite biology is tuned to a specific environmental redox potential, and that the perturbation of redox homeostasis with either oxidative or reductive stress elicits a phenotypic response.

The mechanism for how $\mathrm{H}_{2} \mathrm{O}_{2}$ mobilizes $\mathrm{Ca}^{2+}$ in animals is better understood but the evolutionary distance between vertebrates and T. gondii makes direct comparisons more challenging. T. gondii is more closely related to plants, and shares a more similar signaling toolkit (Nagamune and Sibley, 2006). It has been recently reported that plants possess a cell surface $\mathrm{H}_{2} \mathrm{O}_{2}$ receptor that once activated, triggers a $\mathrm{Ca}^{2+}$ influx into the cells through a $\mathrm{Ca}^{2+}$ ion channel (Wu et al., 2020). T. gondii also has a $\mathrm{H}_{2} \mathrm{O}_{2}$-sensitive protein that associates with the CDPK1 to promote microneme secretion (Child et al., 2017), an event that requires $\mathrm{Ca}^{2+}$ mobilization to allow parasite invasion (Lovett et al., 2002).

Our work suggests a connection between oxidation and parasite $\mathrm{Ca}^{2+}$ release but our data did not find evidence that ionophore-induced $\mathrm{Ca}^{2+}$ release changes the redox state of either the parasite's cytosol or PV. The use of the GRX1-roGFP2 sensor to track redox changes based on GSH/GSSG allows a fast and selective assessment of redox fluctuations in real time (Aller et al., 2013), with improved dynamics compared to other redox sensors like roGFP1 or roGFP2 (Hanson et al., 2004). Considering that $\mathrm{Ca}^{2+}$ mobilization is also a fast event, GRX1roGFP2 is a suitable tool to investigate the relationship between ROS and $\mathrm{Ca}^{2+}$. Moreover, the fact that GRX1 does not directly interact with $\mathrm{H}_{2} \mathrm{O}_{2}$ (Gutscher et al., 2008) implies this sensor would not interfere with any eventual interaction between $\mathrm{H}_{2} \mathrm{O}_{2}$ and its potential targets within the parasite or PV. Unexpectedly, expression of GRX1-roGFP2 within T. gondii parasites was detrimental to asexual replication. This is surprising as the GRX1-based sensor is generally well tolerated, and presents negligible toxicity in neurons (Gutscher et al., 2008; Hasel et al., 2015). Inactivation of the catalytic domain of GRX1 only partially recovered parasite growth, suggesting that roGFP2 alone is sufficient to influence parasite replication. Cells contain millimolar concentrations of GSH within their cytoplasm and organelles, and under physiological conditions the cell maintains the majority of this redox buffer molecule in a reduced form ([GSH] $>$ [GSSG]) (Brieger et al., 2012). Parasites overexpressing GRX1 would be expected to affect the normal GSH/GSSG balance. The addition of NAC, a small molecule that can be used to generate GSH, also slowed parasite growth. This supports the hypothesis that the GSH/GSSG ratio can influence parasite replication. Parasites expressing GRX1ser-roGFP2 are likely have altered redox potential due ability of roGFP2 not fused with an active GRX1 to interact directly with oxidizing molecules like $\mathrm{H}_{2} \mathrm{O}_{2}$ (Liu et al., 2014).

Targeting of the redox sensor to the PV had the greatest effect upon parasite asexual growth. During asexual replication within host cells, T. gondii resides within the PV. This compartment separates the parasite from the host cytoplasm, providing a niche for parasite survival and replication (Clough and Frickel, 2017). Signaling molecules from the host must cross the PV in order to reach the parasite. Should an oxidative signal from the host encounter an unusually reductive environment within the PV due the buffering effect of the redox sensor, the signal could be lost before reaching the parasite. Our work increases our understanding of the complex redox system in T. gondii, and provides the first evidence that parasite replication is sensitive to redox imbalance. Redox clearly has an important role in T. gondii pathophysiology and we anticipate that the unveiling of this network will guide future covalent drug discovery targeting redox-sensitive chemically reactive cysteines.

\section{DATA AVAILABILITY STATEMENT}

The original contributions presented in the study are included in the article/Supplementary Material. Further inquiries can be directed to the corresponding author.

\section{AUTHOR CONTRIBUTIONS}

Conception/design of the work, EA and MC. Acquisition/ analysis/interpretation of data, EA, HB, LM, CD, TD, JB, CW, and MC. Manuscript drafting and revision, EA, HB, CD, CW, and MC. All authors contributed to the article and approved the submitted version.

\section{FUNDING}

This work was supported by grant $202553 / \mathrm{Z} / 16 / \mathrm{Z}$ from the Wellcome Trust \& Royal Society (to MC), and BB/M011178/1 from the BBSRC (to HB and MC).

\section{ACKNOWLEDGMENTS}

We sincerely thank Prof Jake Baum and Dr George Ashdown for the access and assistance to widefield microscopy, Dr Moritz Treeck for the RH-GFP-Luc line, Dr Lilach Sheiner for the roGFP construct, and Dr Gautam Dey for useful discussions. We would also like to thank the Imperial College Flow Cytometry Facility team in South Kensington for technical support. We would like to acknowledge the artistic contribution of Mai Ito who kindly provided the graphical depiction of a T. gondii tachyzoite used in Figure 1. 


\section{SUPPLEMENTARY MATERIAL}

The Supplementary Material for this article can be found online at: https://www.frontiersin.org/articles/10.3389/fcimb.2021.728425/ full\#supplementary-material

Supplementary Table 1 | List of Toxoplasma gondii genes related to redox sensing systems and their primary location based on hyperLOPIT datasets. PITH, proteasome-interacting thioredoxin; ER, endoplasmic reticulum; PM, plasma membrane; GSH, glutathione; NA, not applicable (location not predicted).

Supplementary Table 2 | List of primers used to generate plasmid and check sequence/integration in this study.

Supplementary Video 1 | Intracellular T. gondii tachyzoites mobilize $\mathrm{Ca}^{2+}$ upon addition of $\mathrm{H}_{2} \mathrm{O}_{2}$, followed by egress induced by $\mathrm{A} 23187$. The left panel displays the GFP channel, middle panel the $\mathrm{Ca}^{2+}$ sensor jCaMP1b channel, and the right panel the channel merge. Time (minutes: seconds) is displayed on the left top region of each channel. $100 \mu \mathrm{M}$ of $\mathrm{H}_{2} \mathrm{O}_{2}$ was added to cells at 1:06, and $1 \mu \mathrm{M}$ A23187 was added at 6:51. Video frame rate: 17 frames per second. This video is representative of 27 infected vacuoles from four independent experiments. MOI: 1.

Supplementary Video 2 | Hydrogen peroxide inducing egress of $T$. gondii tachyzoites at low MOI. The left panel displays the GFP channel, the middle panel the $\mathrm{Ca}^{2+}$ sensor jCaMP1b channel, and the right panel the merge. Time (minutes: seconds) is displayed on the left top region of each channel. $100 \mu \mathrm{M}$ of $\mathrm{H}_{2} \mathrm{O}_{2}$ was added to cells at 00:45s. Video frame rate: 10 frames per second. This video presents an egress event captured using low $\mathrm{MOI}(\mathrm{MOI}=1)$.

Supplementary Video 3 | Hydrogen peroxide inducing egress of $T$. gondii tachyzoites at high MOI. The left panel displays the GFP channel, middle panel the $\mathrm{Ca}^{2+}$ sensor jCaMP1b channel, and the right panel the merge. Time (minutes: seconds) is displayed on the left top region of each channel. $100 \mu \mathrm{M}$ of $\mathrm{H}_{2} \mathrm{O}_{2}$ was added to cells at 00:30s. Video frame rate: 15 frames per second. This video is representative of 34 infected vacuoles from three independent experiments (MOI=5).

Supplementary Figure 1 | Fluorescence tracking of $\mathrm{Ca}^{2+}$ signal and GFP movement on RH-GFP-t2a-jRCaMP1b parasites within host cell. (A, B) Representative trace of parasite vacuoles following treatment with $\mathrm{H}_{2} \mathrm{O}_{2}$ and ionophore A23187. (A) The graph presents the independent GFP trace (green) and $\mathrm{Ca}^{2+}$ signal from jRCaMP1b sensor (red). Note the parasite movement at 420 s. (B) Graph of the $\mathrm{Ca}^{2+}$ signal is normalized to GFP to minimize artefact on the $\mathrm{Ca}^{2+}$ measurements due to parasite movement. Red arrow indicates the moment of parasite egress. (C) Water, the vehicle solvent for $\mathrm{H}_{2} \mathrm{O}_{2}$, does not mobilize $\mathrm{Ca}^{2+}$. The graph displays the trace of three independent vacuoles from the same field of view. Data are representative of 15 infected vacuoles from four independent experiments. (D) DMSO, the vehicle solvent for ionophore A23187, does not mobilize $\mathrm{Ca}^{2+}$. The graph displays the trace of four independent infected vacuoles from the same field of view. Data are representative of 12 rosettes

\section{REFERENCES}

Akerman, S. E., and Muller, S. (2005). Peroxiredoxin-Linked Detoxification of Hydroperoxides in Toxoplasma Gondii. J. Biol. Chem. 280 (1), 564-570. doi: 10.1074/jbc.M406367200

Aller, I., Rouhier, N., and Meyer, A. J. (2013). Development of Rogfp2-Derived Redox Probes for Measurement of the Glutathione Redox Potential in the Cytosol of Severely Glutathione-Deficient Rml1 Seedlings. Front. Plant Sci. 4, 506. doi: $10.3389 /$ fpls.2013.00506

Augusto, L., Martynowicz, J., Amin, P. H., Carlson, K. R., Wek, R. C., and Sullivan, W. J. (2021). TgIF2K-B Is an eIF2 $\alpha$ Kinase in Toxoplasma Gondii That Responds to Oxidative Stress and Optimizes Pathogenicity. mBio 12 (1), e03160-20. doi: 10.1128/mBio.03160-20

Avdonin, P. V., Nadeev, A. D., Tsitrin, E. B., Tsitrina, A. A., Avdonin, P. P., Mironova, G. Y., et al. (2017). Involvement of Two-Pore Channels in from three independent experiments. (A-D) black arrows indicate the time of drug/solvent addition.

Supplementary Figure 2 | Quantification of RH-GFP-T2A-jCamP1b parasite egress by flow cytometry. (A) Representative gating using GFP (Blue laser, 488nm, filter 530/30) against Forward scatter (FSC-A). HFF water control: uninfected human foreskin fibroblast (HFF) are mainly localised in quadrant $\underline{\mathrm{c}}$. Lysed tachyzoites: free RH-GFP-T2A-jCamP1b parasites are mainly localised in quadrant a. iHFF water control: infected host cells are detected in quadrant $\underline{b}$. By using the GFP it is possible to distinguish free fluorescent parasite from HFF in a population and assess the egress rates throughout different treatments. (B) Effect of drug incubation on non-infected HFF. The graph presents a change on event number within the non-fluorescent HFF gate. Data represent the mean \pm SEM of three independent experiments (except for DMSO treatment that has two independent experiment), six technical replicates on each. Significance was calculated using one-way Anova, Bonferroni's multiple comparisons $\mathrm{P}$ value ${ }^{* \star *}<0.001$.

Supplementary Figure 3 | Exploring the redox sensitivity of RH-GRX1-roGFP2 parasites to $\mathrm{H}_{2} \mathrm{O}_{2}$. (A) Tracking the GSH/GSSG change upon different concentration of $\mathrm{H}_{2} \mathrm{O}_{2}$. Among the concentration tested, $10 \mu \mathrm{M}$ was the only one that did not induce a change in redox within the parasite cytosol. Data are representative of five infected vacuoles from each concentration, one independent experiment. (B) Water (vehicle control for $\mathrm{H}_{2} \mathrm{O}_{2}$ ) and DMSO (vehicle control for A23187) do not trigger change in GSH/GSSG. Data are representative of 12 vacuoles from three independent experiments. (C) Autofluorescence effect of A23187 drug on oxidation channel makes this ionophore unsuitable for ratiometric analyses of GRX1-roGFP2 sensor. Widefield microscope imaging depicting an egress induce by A23187. The structure of A23187 is shown.

Supplementary Figure 4 | Inactivation of the catalytic domain of glutaredoxin 1 makes the GRX1-roGFP2 redox sensor insensitive to changes in GSH/GSSH. Parasite expressing GRX1ser-roGFP2 do not display fluorescent changes in either channel (reduction or oxidation) upon addition of $\mathrm{H}_{2} \mathrm{O}_{2}$. Data are representative of 12 infected vacuole, three independent experiments. Black arrows indicate the time of $\mathrm{H}_{2} \mathrm{O}_{2}$ addition.

Supplementary Figure 5 | Toxoplasma parasites RH-GFP-Luc and $\mathrm{RH} \Delta k 480 \Delta H X G P R T$ plaque with similar efficiency. Bar graphs presenting plaque count data from a six-day plaque assay. The data presented is from three independent biological experiments, each with three technical replicates. No statistically significant difference was found between the two strains using two-tailed paired Student $t$ test.

Supplementary Figure 6 | Effect of redox sensors on T. gondii parasite growth. Each graph presents parasites/vacuole counts after 20 hours of intracellular growth. The mean values are displayed over each bar for three independent experiments. (A) Percentage (\%) of vacuoles contain one parasite. (B) \% of vacuoles with two parasites. (C) \% of vacuoles with four parasites. (D) \% of vacuoles with eight parasites. (E) \% of vacuoles with 16 parasites. (F) \% of vacuoles with more than 32 parasites. Significance was calculated using two-way Anova, Bonferroni's multiple comparisons test. P values: ${ }^{\star}<0.05 ;{ }^{* \star}<0.01,{ }^{\star \star \star}<0.001$ and ${ }^{\star \star \star \star}<0.0001$.

Hydrogen Peroxide-Induced Increase in the Level of Calcium Ions in the Cytoplasm of Human Umbilical Vein Endothelial Cells. Dokl. Biochem. Biophys. 474 (1), 209-212. doi: 10.1134/S1607672917030152

Barylyuk, K., Koreny, L., Ke, H., Butterworth, S., Crook, O. M., Lassadi, I., et al. (2020). A Comprehensive Subcellular Atlas of the Toxoplasma Proteome Via hyperLOPIT Provides Spatial Context for Protein Functions. Cell Host Microbe 28 (5), 752-66 e9. doi: 10.1016/.j.chom.2020.09.011

Behnke, M. S., Zhang, T. P., Dubey, J. P., and Sibley, L. D. (2014). Toxoplasma Gondii Merozoite Gene Expression Analysis With Comparison to the Life Cycle Discloses a Unique Expression State During Enteric Development. BMC Genomics 15, 350. doi: 10.1186/1471-2164-15-350

Biddau, M., Bouchut, A., Major, J., Saveria, T., Tottey, J., Oka, O., et al. (2018). Two Essential Thioredoxins Mediate Apicoplast Biogenesis, Protein Import, and Gene Expression in Toxoplasma Gondii. PloS Pathog. 14 (2), e1006836. doi: 10.1371/journal.ppat.1006836 
Black, M. W., Arrizabalaga, G., and Boothroyd, J. C. (2000). Ionophore-Resistant Mutants of Toxoplasma Gondii Reveal Host Cell Permeabilization as an Early Event in Egress. Mol. Cell Biol. 20 (24), 9399-9408. doi: 10.1128/ MCB.20.24.9399-9408.2000

Brieger, K., Schiavone, S., Miller, F. J.Jr., and Krause, K. H. (2012). Reactive Oxygen Species: From Health to Disease. Swiss Med. Wkly. 142, w13659. doi: 10.4414/smw.2012.13659

Brown, K. M., Lourido, S., and Sibley, L. D. (2016). Serum Albumin Stimulates Protein Kinase G-Dependent Microneme Secretion in Toxoplasma Gondii. J. Biol. Chem. 291 (18), 9554-9565. doi: 10.1074/jbc.M115.700518

Bullen, H. E., Bisio, H., and Soldati-Favre, D. (2019). The Triumvirate of Signaling Molecules Controlling Toxoplasma Microneme Exocytosis: Cyclic GMP, Calcium, and Phosphatidic Acid. PloS Pathog. 15 (5), e1007670. doi: 10.1371/journal.ppat.1007670

Bullen, H. E., Jia, Y., Yamaryo-Botte, Y., Bisio, H., Zhang, O., Jemelin, N. K., et al. (2016). Phosphatidic Acid-Mediated Signaling Regulates Microneme Secretion in Toxoplasma. Cell Host Microbe 19 (3), 349-360. doi: 10.1016/ j.chom.2016.02.006

Caffaro, C. E., Koshy, A. A., Liu, L., Zeiner, G. M., Hirschberg, C. B., and Boothroyd, J. C. (2013). A Nucleotide Sugar Transporter Involved in Glycosylation of the Toxoplasma Tissue Cyst Wall Is Required for Efficient Persistence of Bradyzoites. PloS Pathog. 9 (5), e1003331. doi: 10.1371/ journal.ppat.1003331

Carey, K. L., Donahue, C. G., and Ward, G. E. (2000). Identification and Molecular Characterization of GRA8, a Novel, Proline-Rich, Dense Granule Protein of Toxoplasma Gondii. Mol. Biochem. Parasitol. 105 (1), 25-37. doi: 10.1016/ S0166-6851(99)00160-7

Carter, S. B. (1967). Effects of Cytochalasins on Mammalian Cells. Nature 213 (5073), 261-264. doi: 10.1038/213261a0

Child, M. A., Garland, M., Foe, I., Madzelan, P., Treeck, M., van der Linden, W. A., et al. (2017). Toxoplasma DJ-1 Regulates Organelle Secretion by a Direct Interaction With Calcium-Dependent Protein Kinase 1. mBio 8 (1), e0218916. doi: $10.1128 / \mathrm{mBio} .02189-16$

Clough, B., and Frickel, E. M. (2017). The Toxoplasma Parasitophorous Vacuole: An Evolving Host-Parasite Frontier. Trends Parasitol. 33 (6), 473-488. doi: 10.1016/j.pt.2017.02.007

Cooke, E., Al-Mohanna, F. A., and Hallett, M. B. (1987). Diacylglycerol Kinase Inhibitor, R59022, Potentiates Neutrophil Oxidase Activation by Ca2 +-Dependent Stimuli. Evidence for Two Separate But Convergent Pathways. Biochem. Pharmacol. 36 (20), 3459-3462. doi: 10.1016/0006-2952(87)90326-1

Coppens, I., Dunn, J. D., Romano, J. D., Pypaert, M., Zhang, H., Boothroyd, J. C., et al. (2006). Toxoplasma Gondii Sequesters Lysosomes From Mammalian Hosts in the Vacuolar Space. Cell 125 (2), 261-274. doi: 10.1016/ j.cell.2006.01.056

Crook, O. M., Mulvey, C. M., Kirk, P. D. W., Lilley, K. S., and Gatto, L. (2018). A Bayesian Mixture Modelling Approach for Spatial Proteomics. PloS Comput. Biol. 14 (11), e1006516. doi: 10.1371/journal.pcbi.1006516

Dana, H., Mohar, B., Sun, Y., Narayan, S., Gordus, A., Hasseman, J. P., et al. (2016). Sensitive Red Protein Calcium Indicators for Imaging Neural Activity. Elife 5, e12727. doi: 10.7554/eLife.1272

Ding, M., Kwok, L. Y., Schluter, D., Clayton, C., and Soldati, D. (2004). The Antioxidant Systems in Toxoplasma Gondii and the Role of Cytosolic Catalase in Defence Against Oxidative Injury. Mol. Microbiol. 51 (1), 47-61. doi: 10.1046/j.1365-2958.2003.03823.x

Di Virgilio, F., Steinberg, T. H., and Silverstein, S. C. (1990). Inhibition of Fura-2 Sequestration and Secretion With Organic Anion Transport Blockers. Cell Calcium 11 (2-3), 57-62. doi: 10.1016/0143-4160(90)90059-4

Dubey, J. P. (1996). WAAP and Pfizer Award for Excellence in Veterinary Parasitology Research. Pursuing Life Cycles and Transmission of CystForming Coccidia of Animals and Humans. Vet. Parasitol. 64 (1-2), 13-20. doi: 10.1016/0304-4017(96)00960-0

Dupre-Crochet, S., Erard, M., and Nubetae, O. (2013). ROS Production in Phagocytes: Why, When, and Where? J. Leukoc. Biol. 94 (4), 657-670. doi: 10.1189/jlb.1012544

Endo, T., Sethi, K. K., and Piekarski, G. (1982). Toxoplasma Gondii: Calcium Ionophore A23187-Mediated Exit of Trophozoites From Infected Murine Macrophages. Exp. Parasitol. 53 (2), 179-188. doi: 10.1016/0014-4894(82) 90059-5
Ezerina, D., Takano, Y., Hanaoka, K., Urano, Y., and Dick, T. P. (2018). N-Acetyl Cysteine Functions as a Fast-Acting Antioxidant by Triggering Intracellular H2S and Sulfane Sulfur Production. Cell Chem. Biol. 25 (4), 4474-59.e4. doi: 10.1016/j.chembiol.2018.01.011

Flegr, J., Prandota, J., Sovickova, M., and Israili, Z. H. (2014). Toxoplasmosis-a Global Threat. Correlation of Latent Toxoplasmosis With Specific Disease Burden in a Set of 88 Countries. PloS One 9 (3), e90203. doi: 10.1371/ journal.pone.0090203

Gajria, B., Bahl, A., Brestelli, J., Dommer, J., Fischer, S., Gao, X., et al. (2008). ToxoDB: An Integrated Toxoplasma Gondii Database Resource. Nucleic Acids Res. 36 (Database issue), D553-D556. doi: 10.1093/nar/gkm981

Garrison, E., Treeck, M., Ehret, E., Butz, H., Garbuz, T., Oswald, B. P., et al. (2012). A Forward Genetic Screen Reveals That Calcium-Dependent Protein Kinase 3 Regulates Egress in Toxoplasma. PloS Pathog. 8 (11), e1003049. doi: 10.1371/ journal.ppat.1003049

Goldman, M., Carver, R. K., and Sulzer, A. J. (1958). Reproduction of Toxoplasma Gondii by Internal Budding. J. Parasitol. 44 (2), 161-171. doi: 10.2307/3274692

Gutscher, M., Pauleau, A. L., Marty, L., Brach, T., Wabnitz, G. H., Samstag, Y., et al. (2008). Real-Time Imaging of the Intracellular Glutathione Redox Potential. Nat. Methods 5 (6), 553-559. doi: 10.1038/nmeth.1212

Gutscher, M., Sobotta, M. C., Wabnitz, G. H., Ballikaya, S., Meyer, A. J., Samstag, Y., et al. (2009). Proximity-Based Protein Thiol Oxidation by $\mathrm{H} 2 \mathrm{O} 2$ Scavenging Peroxidases. J. Biol. Chem. 284 (46), 31532-31540. doi: 10.1074/ jbc.M109.059246

Guzik, T. J., West, N. E., Black, E., McDonald, D., Ratnatunga, C., Pillai, R., et al. (2000). Vascular Superoxide Production by NAD(P)H Oxidase: Association With Endothelial Dysfunction and Clinical Risk Factors. Circ. Res. 86 (9), E85E90. doi: 10.1161/01.RES.86.9.e85

Halonen, S. K., and Weiss, L. M. (2013). Toxoplasmosis. Handb. Clin. Neurol. 114, 125-145. doi: 10.1016/B978-0-444-53490-3.00008-X

Hanson, G. T., Aggeler, R., Oglesbee, D., Cannon, M., Capaldi, R. A., Tsien, R. Y., et al. (2004). Investigating Mitochondrial Redox Potential With RedoxSensitive Green Fluorescent Protein Indicators. J. Biol. Chem. 279 (13), 13044-13053. doi: 10.1074/jbc.M312846200

Hasel, P., McKay, S., Qiu, J., and Hardingham, G. E. (2015). Selective Dendritic Susceptibility to Bioenergetic, Excitotoxic and Redox Perturbations in Cortical Neurons. Biochim. Biophys. Acta 1853 (9), 2066-2076. doi: 10.1016/ j.bbamcr.2014.12.021

Hyslop, P. A., Hinshaw, D. B., Scraufstatter, I. U., Cochrane, C. G., Kunz, S., and Vosbeck, K. (1995). Hydrogen Peroxide as a Potent Bacteriostatic Antibiotic: Implications for Host Defense. Free Radic. Biol. Med. 19 (1), 31-37. doi: 10.1016/0891-5849(95)00005-I

Kaasch, A. J., and Joiner, K. A. (2000). Targeting and Subcellular Localization of Toxoplasma Gondii Catalase. Identification of Peroxisomes in an Apicomplexan Parasite. J. Biol. Chem. 275 (2), 1112-1118. doi: 10.1074/ jbc.275.2.1112

Laporte, D., Olate, E., Salinas, P., Salazar, M., Jordana, X., and Holuigue, L. (2012). Glutaredoxin GRXS13 Plays a Key Role in Protection Against Photooxidative Stress in Arabidopsis. J. Exp. Bot. 63 (1), 503-515. doi: 10.1093/jxb/err301

Lima, T. S., and Lodoen, M. B. (2019). Mechanisms of Human Innate Immune Evasion by Toxoplasma Gondii. Front. Cell Infect. Microbiol. 9, 103. doi: 10.3389/fcimb.2019.00103

Liu, X., Wu, J., Liu, H., Zong, N., and Zhao, J. (2014). RoGFP1 Is a Quantitative Biosensor in Maize Cells for Cellular Redox Changes Caused by Environmental and Endogenous Stimuli. Biochem. Biophys. Res. Commun. 452 (3), 503-508. doi: 10.1016/j.bbrc.2014.08.107

Lourido, S., and Moreno, S. N. (2015). The Calcium Signaling Toolkit of the Apicomplexan Parasites Toxoplasma Gondii and Plasmodium Spp. Cell Calcium 57 (3), 186-193. doi: 10.1016/j.ceca.2014.12.010

Lovett, J. L., Marchesini, N., Moreno, S. N., and Sibley, L. D. (2002). Toxoplasma Gondii Microneme Secretion Involves Intracellular $\mathrm{Ca}(2+)$ Release From Inositol 1,4,5-Triphosphate (IP(3))/ryanodine-Sensitive Stores. J. Biol. Chem. 277 (29), 25870-25876. doi: 10.1074/jbc.M202553200

Luder, C. G., and Gross, U. (2005). Apoptosis and its Modulation During Infection With Toxoplasma Gondii: Molecular Mechanisms and Role in Pathogenesis. Curr. Top. Microbiol. Immunol. 289, 219-237. doi: 10.1007/3-540-27320-4_10 Luder, C. G., Stanway, R. R., Chaussepied, M., Langsley, G., and Heussler, V. T. (2009). Intracellular Survival of Apicomplexan Parasites and Host Cell 
Modification. Int. J. Parasitol. 39 (2), 163-173. doi: 10.1016/j.ijpara. 2008.09.013

Luft, B. J., and Remington, J. S. (1992). Toxoplasmic Encephalitis in AIDS. Clin. Infect. Dis. 15 (2), 211-222. doi: 10.1093/clinids/15.2.211

McLeod, R., Estes, R., Mack, D. G., and McLeod, E. G. (1983). Effects of Human Alveolar Macrophages and Peripheral Blood Monocytes on Toxoplasma Gondii. J. Infect. Dis. 147 (5), 957. doi: 10.1093/infdis/147.5.957

Meissner, G. (2002). Regulation of Mammalian Ryanodine Receptors. Front. Biosci. 7, d2072-d2080. doi: 10.2741/a899

Meyer, A. J., Brach, T., Marty, L., Kreye, S., Rouhier, N., Jacquot, J. P., et al. (2007). Redox-Sensitive GFP in Arabidopsis Thaliana Is a Quantitative Biosensor for the Redox Potential of the Cellular Glutathione Redox Buffer. Plant J. 52 (5), 973-986. doi: 10.1111/j.1365-313X.2007.03280.x

Montoya, J. G., and Liesenfeld, O. (2004). Toxoplasmosis. Lancet 363 (9425), 1965-1976. doi: 10.1016/S0140-6736(04)16412-X

Murphy, R. C., Ojo, K. K., Larson, E. T., Castellanos-Gonzalez, A., Perera, B. G., Keyloun, K. R., et al. (2010). Discovery of Potent and Selective Inhibitors of Calcium-Dependent Protein Kinase 1 (CDPK1) From C. Parvum and T. Gondii. ACS Med. Chem. Lett. 1 (7), 331-335. doi: 10.1021/ml100096t

Murray, H. W., and Cohn, Z. A. (1979). Macrophage Oxygen-Dependent Antimicrobial Activity. I. Susceptibility of Toxoplasma Gondii to Oxygen Intermediates. J. Exp. Med. 150 (4), 938-949. doi: 10.1084/jem.150.4.938

Nagamune, K., and Sibley, L. D. (2006). Comparative Genomic and Phylogenetic Analyses of Calcium ATPases and Calcium-Regulated Proteins in the Apicomplexa. Mol. Biol. Evol. 23 (8), 1613-1627. doi: 10.1093/molbev/msl026

Oda, T., Yang, Y., Uchinoumi, H., Thomas, D. D., Chen-Izu, Y., Kato, T., et al. (2015). Oxidation of Ryanodine Receptor (RyR) and Calmodulin Enhance Ca Release and Pathologically Alter, RyR Structure and Calmodulin Affinity. J. Mol. Cell Cardiol. 85, 240-248. doi: 10.1016/j.yjmcc.2015.06.009

Odberg-Ferragut, C., Renault, J. P., Viscogliosi, E., Toursel, C., Briche, I., Engels, A., et al. (2000). Molecular Cloning, Expression Analysis and Iron Metal Cofactor Characterisation of a Superoxide Dismutase From Toxoplasma Gondii. Mol. Biochem. Parasitol. 106 (1), 121-129. doi: 10.1016/S0166-6851(99)00211-X

Ojo, K. K., Larson, E. T., Keyloun, K. R., Castaneda, L. J., Derocher, A. E., Inampudi, K. K., et al. (2010). Toxoplasma Gondii Calcium-Dependent Protein Kinase 1 is a Target for Selective Kinase Inhibitors. Nat. Struct. Mol. Biol. 17 (5), 602-607. doi: 10.1038/nsmb.1818

Pace, D. A., McKnight, C. A., Liu, J., Jimenez, V., and Moreno, S. N. (2014). Calcium Entry in Toxoplasma Gondii and its Enhancing Effect of Invasion-Linked Traits. J. Biol. Chem. 289 (28), 19637-19647. doi: 10.1074/jbc.M114.565390

Pastore, A., and Piemonte, F. (2012). S-Glutathionylation Signaling in Cell Biology: Progress and Prospects. Eur. J. Pharm. Sci. 46 (5), 279-292. doi: 10.1016/j.ejps.2012.03.010

Ploemen, I. H., Prudencio, M., Douradinha, B. G., Ramesar, J., Fonager, J., van Gemert, G. J., et al. (2009). Visualisation and Quantitative Analysis of the Rodent Malaria Liver Stage by Real Time Imaging. PloS One 4 (11), e7881. doi: 10.1371/journal.pone.0007881

Popov, D. (2014). Protein S-Glutathionylation: From Current Basics to Targeted Modifications. Arch. Physiol. Biochem. 120 (4), 123-130. doi: 10.3109/ 13813455.2014.944544

Reese, M. L., Zeiner, G. M., Saeij, J. P., Boothroyd, J. C., and Boyle, J. P. (2011). Polymorphic Family of Injected Pseudokinases Is Paramount in Toxoplasma Virulence. Proc. Natl. Acad. Sci. U.S.A. 108 (23), 9625-9630. doi: 10.1073/ pnas. 1015980108

Roveri, A., Coassin, M., Maiorino, M., Zamburlini, A., van Amsterdam, F. T., Ratti, E., et al. (1992). Effect of Hydrogen Peroxide on Calcium Homeostasis in Smooth Muscle Cells. Arch. Biochem. Biophys. 297 (2), 265-270. doi: 10.1016/ 0003-9861(92)90671-I

Sabens Liedhegner, E. A., Gao, X. H., and Mieyal, J. J. (2012). Mechanisms of Altered Redox Regulation in Neurodegenerative Diseases-Focus on Sglutathionylation. Antioxid. Redox Signal. 16 (6), 543-566. doi: 10.1089/ ars.2011.4119

Sautel, C. F., Ortet, P., Saksouk, N., Kieffer, S., Garin, J., Bastien, O., et al. (2009). The Histone Methylase KMTox Interacts With the Redox-Sensor Peroxiredoxin-1 and Targets Genes Involved in Toxoplasma Gondii Antioxidant Defences. Mol. Microbiol. 71 (1), 212-226. doi: 10.1111/j.1365-2958.2008.06519.x

Sheffield, H. G., and Melton, M. L. (1968). The Fine Structure and Reproduction of Toxoplasma Gondii. J. Parasitol. 54 (2), 209-226. doi: 10.2307/3276925
Shrestha, S. P., Tomita, T., Weiss, L. M., and Orlofsky, A. (2006). Proliferation of Toxoplasma Gondii in Inflammatory Macrophages In Vivo Is Associated With Diminished Oxygen Radical Production in the Host Cell. Int. J. Parasitol. 36 (4), 433-441. doi: 10.1016/j.ijpara.2006.01.006

Sibley, L. D., Krahenbuhl, J. L., and Weidner, E. (1985). Lymphokine Activation of J774G8 Cells and Mouse Peritoneal Macrophages Challenged With Toxoplasma Gondii. Infect. Immun. 49 (3), 760-764. doi: 10.1128/iai.49.3.760-764.1985

Sibley, L. D., Lawson, R., and Weidner, E. (1986). Superoxide Dismutase and Catalase in Toxoplasma Gondii. Mol. Biochem. Parasitol. 19 (1), 83-87. doi: 10.1016/0166-6851(86)90069-1

Silverman, J. A., Qi, H., Riehl, A., Beckers, C., Nakaar, V., and Joiner, K. A. (1998). Induced Activation of the Toxoplasma Gondii Nucleoside Triphosphate Hydrolase Leads to Depletion of Host Cell ATP Levels and Rapid Exit of Intracellular Parasites From Infected Cells. J. Biol. Chem. 273 (20), 12352 12359. doi: $10.1074 / \mathrm{jbc} .273 .20 .12352$

Soldati, D., and Boothroyd, J. C. (1993). Transient Transfection and Expression in the Obligate Intracellular Parasite Toxoplasma Gondii. Science 260 (5106), 349-352. doi: 10.1126/science.8469986

Stewart, R. J., Whitehead, L., Nijagal, B., Sleebs, B. E., Lessene, G., McConville, M. J., et al. (2017). Analysis of $\mathrm{Ca}(2)(+)$ Mediated Signaling Regulating Toxoplasma Infectivity Reveals Complex Relationships Between Key Molecules. Cell Microbiol. 19 (4), e12685. doi: 10.1111/cmi.12685

Stommel, E. W., Ely, K. H., Schwartzman, J. D., and Kasper, L. H. (1997). Toxoplasma Gondii: Dithiol-Induced Ca2+ Flux Causes Egress of Parasites From the Parasitophorous Vacuole. Exp. Parasitol. 87 (2), 88-97. doi: 10.1006/ expr.1997.4187

Sun, C., Berardi, M. J., and Bushweller, J. H. (1998). The NMR Solution Structure of Human Glutaredoxin in the Fully Reduced Form. J. Mol. Biol. 280 (4), 687701. doi: 10.1006/jmbi.1998.1913

Treeck, M., Sanders, J. L., Gaji, R. Y., LaFavers, K. A., Child, M. A., Arrizabalaga, G., et al. (2014). The Calcium-Dependent Protein Kinase 3 of Toxoplasma Influences Basal Calcium Levels and Functions Beyond Egress as Revealed by Quantitative Phosphoproteome Analysis. PloS Pathog. 10 (6), e1004197. doi: 10.1371/journal.ppat.1004197

Veal, E., and Day, A. (2011). Hydrogen Peroxide as a Signaling Molecule. Antioxid. Redox Signal. 15 (1), 147-151. doi: 10.1089/ars.2011.3968

Vieira, M. C., and Moreno, S. N. (2000). Mobilization of Intracellular Calcium Upon Attachment of Toxoplasma Gondii Tachyzoites to Human Fibroblasts Is Required for Invasion. Mol. Biochem. Parasitol. 106 (1), 157-162. doi: 10.1016/ S0166-6851(99)00182-6

Volk, T., Hensel, M., and Kox, W. J. (1997). Transient Ca2+ Changes in Endothelial Cells Induced by Low Doses of Reactive Oxygen Species: Role of Hydrogen Peroxide. Mol. Cell Biochem. 171 (1-2), 11-21. doi: 10.1023/A:1006886215193

Weiss, L. M., and Dubey, J. P. (2009). Toxoplasmosis: A History of Clinical Observations. Int. J. Parasitol. 39 (8), 895-901. doi: 10.1016/j.ijpara.2009.02.004

Wetzel, D. M., Chen, L. A., Ruiz, F. A., Moreno, S. N., and Sibley, L. D. (2004). Calcium-Mediated Protein Secretion Potentiates Motility in Toxoplasma Gondii. J. Cell Sci. 117 (Pt 24), 5739-5748. doi: 10.1242/jcs.01495

Wilson, C. B., Tsai, V., and Remington, J. S. (1980). Failure to Trigger the Oxidative Metabolic Burst by Normal Macrophages: Possible Mechanism for Survival of Intracellular Pathogens. J. Exp. Med. 151 (2), 328-346. doi: 10.1084/ jem.151.2.328

Winterbourn, C. C., and Hampton, M. B. (2008). Thiol Chemistry and Specificity in Redox Signaling. Free Radic. Biol. Med. 45 (5), 549-561. doi: 10.1016/ j.freeradbiomed.2008.05.004

Wu, F., Chi, Y., Jiang, Z., Xu, Y., Xie, L., Huang, F., et al. (2020). Hydrogen Peroxide Sensor HPCA1 Is an LRR Receptor Kinase in Arabidopsis. Nature 578 (7796), 577-581. doi: 10.1038/s41586-020-2032-3

Xiong, Y., Uys, J. D., Tew, K. D., and Townsend, D. M. (2011). SGlutathionylation: From Molecular Mechanisms to Health Outcomes. Antioxid. Redox Signal. 15 (1), 233-270. doi: 10.1089/ars.2010.3540

Xue, J., Jiang, W., Chen, Y., Gong, F., Wang, M., Zeng, P., et al. (2017). Thioredoxin Reductase From Toxoplasma Gondii: An Essential Virulence Effector With Antioxidant Function. FASEB J. 31 (10), 4447-4457. doi: 10.1096/fj.201700008R

Yang, Y., Jao, S., Nanduri, S., Starke, D. W., Mieyal, J. J., and Qin, J. (1998). Reactivity of the Human Thioltransferase (Glutaredoxin) C7S, C25S, C78S, C82S Mutant and NMR Solution Structure of its Glutathionyl Mixed Disulfide 
Intermediate Reflect Catalytic Specificity. Biochemistry 37 (49), 17145-17156. doi: 10.1021/bi9806504

Conflict of Interest: The authors declare that the research was conducted in the absence of any commercial or financial relationships that could be construed as a potential conflict of interest.

Publisher's Note: All claims expressed in this article are solely those of the authors and do not necessarily represent those of their affiliated organizations, or those of the publisher, the editors and the reviewers. Any product that may be evaluated in this article, or claim that may be made by its manufacturer, is not guaranteed or endorsed by the publisher.

Copyright @ 2021 Alves, Benns, Magnus, Dominicus, Dobai, Blight, Wincott and Child. This is an open-access article distributed under the terms of the Creative Commons Attribution License (CC BY). The use, distribution or reproduction in other forums is permitted, provided the original author(s) and the copyright owner(s) are credited and that the original publication in this journal is cited, in accordance with accepted academic practice. No use, distribution or reproduction is permitted which does not comply with these terms. 